\title{
Ascaris suum Informs Extrasynaptic Volume Transmission in Nematodes
}

Louise E. Atkinson, Yang Liu, Fiona McKay, Elke Vandewyer, Charles Viau, Allister Irvine, Bruce A. Rosa, Zihui Li, Qingxiao Liang, Nikki J. Marks, Aaron G. Maule, Makedonka Mitreva, Isabel Beets, Lingjun Li, and Angela Mousley*

Cite This: ACS Chem. Neurosci. 2021, 12, 3176-3188

Read Online

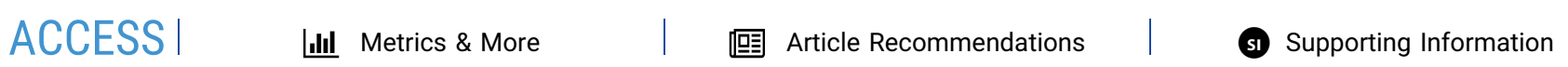

ABSTRACT: Neural circuit synaptic connectivities (the connectome) provide the anatomical foundation for our understanding of nematode nervous system function. However, other nonsynaptic routes of communication are known in invertebrates including extrasynaptic volume transmission (EVT), which enables short- and/or longrange communication in the absence of synaptic connections. Although EVT has been highlighted as a facet of Caenorhabditis elegans neurosignaling, no experimental evidence identifies body cavity fluid (pseudocoelomic fluid; PCF) as a vehicle for either neuropeptide or biogenic amine transmission. In the parasitic nematode Ascaris suum, FMRFamide-like peptides encoded on $f l p-18$ potently stimulate female reproductive organs but are expressed in cells that are anatomically distant from the reproductive organ, with no known synaptic connections to this tissue. Here we investigate nonsynaptic neuropeptide signaling in nematodes mediated by the body cavity fluid. Our data show that (i) A. suum PCF (As-PCF) contains a catalog of neuropeptides including FMRFamide-like peptides and neuropeptide-like proteins, (ii) the A. suum FMRFamide-

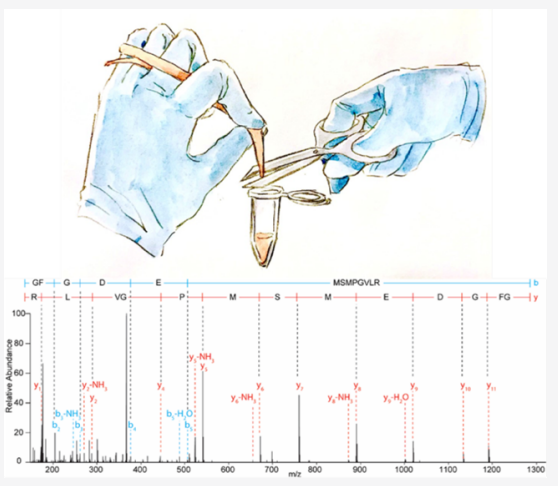
like peptide As-FLP-18A dominates the As-PCF peptidome, (iii) As-PCF potently modulates nematode reproductive muscle function ex vivo, mirroring the effects of synthetic FLP-18 peptides, (iv) As-PCF activates the C. elegans FLP-18 receptors NPR-4 and -5, (v) As-PCF alters C. elegans behavior, and (vi) FLP-18 and FLP-18 receptors display pan-phylum distribution in nematodes. This study provides the first direct experimental evidence to support an extrasynaptic volume route for neuropeptide transmission in nematodes. These data indicate nonsynaptic signaling within the nematode functional connectome and are particularly pertinent to receptor deorphanization approaches underpinning drug discovery programs for nematode pathogens.

KEYWORDS: Extrasynaptic volume transmission, pseudocoelomic fluid, neuropeptide, neuronal signaling, nematode, parasite, Ascaris

\section{INTRODUCTION}

Our current understanding of nematode neuronal circuitry is based on comprehensive Caenorhabditis elegans synaptic connectome data. ${ }^{1-3}$ The $C$. elegans blueprint underpins fundamental parasitic nematode neurobiology driving anatomical and functional connectomics studies in model parasites such as Ascaris suum, in which the simple neuronal architecture described in C. elegans appears to be highly conserved; see ref 4. While not directly experimentally demonstrated in nematodes to date, the existence and significance of additional forms of nonsynaptic neuronal communication have been widely recognized among invertebrates. ${ }^{5,6}$ For example, in crustaceans, extrasynaptic volume transmission (EVT) operates beyond the synaptic connectome, mediating long-range hormonal communication in the absence of neuronal synapses. $^{7,8}$ Notably, EVT has also been implicated in nematode neuronal signaling including in C. elegans. ${ }^{9-14}$ Indeed, the $C$. elegans wired connectome does not always support receptor-ligand interactions that have been functionally linked; there are examples of signaling pathways where receptors are not located cosynaptically with neurons in both monoamine and neuropeptide systems, ${ }^{15-18}$ supporting a role for EVT in neurotransmission. Further, EVT has been putatively linked to nematode neuropeptide signaling via in silico approaches that exploit gene expression data to map putative neuronal connections. ${ }^{19}$

Neuropeptides are well-known neuromodulators of a wide array of essential neuronal functions in nematodes, including locomotion, reproduction, and feeding, highlighting the importance of neuropeptidergic signaling to nematode biology. $^{20,21}$ Despite this, neuropeptide signaling remains unexploited underscoring its appeal as a novel control target.

Received: April 30, 2021

Accepted: July 19, 2021

Published: August 4, 2021 
A

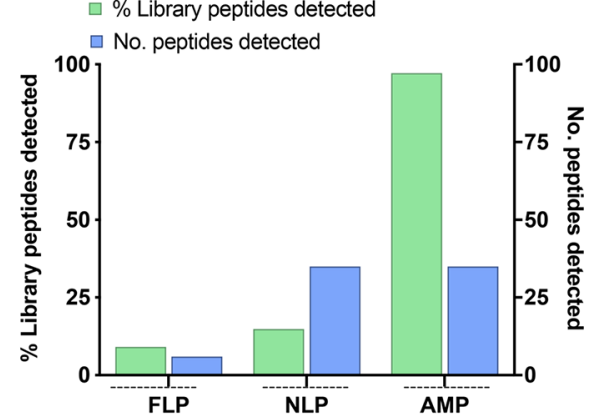

C

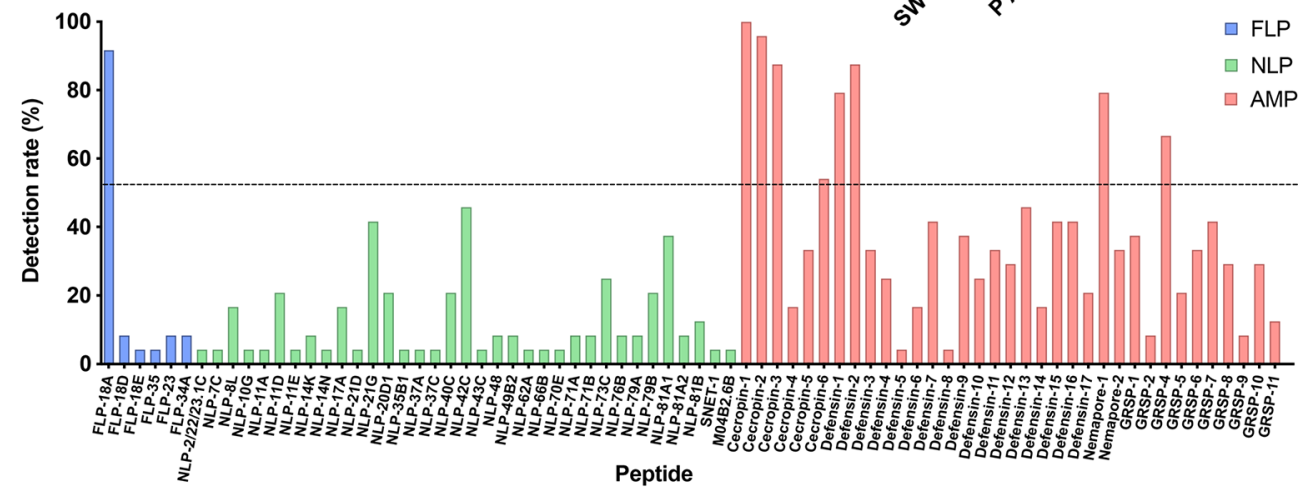

D i

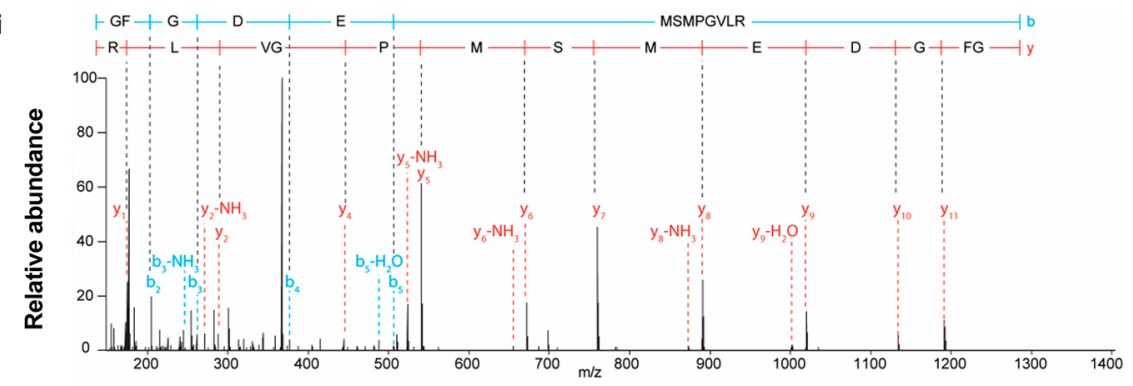

ii

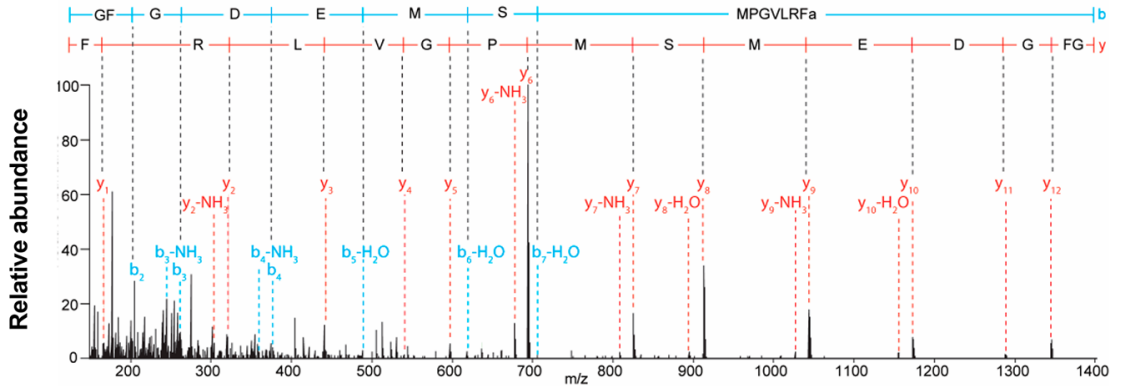

Figure 1. Ascaris suum pseudocoelomic fluid (As-PCF) contains a rich neuropeptide library. (A) 41 neuropeptides, including 6 FMRFamide-like peptides (FLPs) and 35 neuropeptide-like proteins (NLPs), and 35 antimicrobial peptides (AMPs) are present in As-PCF ( $n=24$ LC-MS/MS runs representing 67 individual worms; combined data from single worm, pooled female and male samples). This represents $9.09 \%$, 14.89\%, and 97.20\% of FLP, NLP, and AMP peptides (respectively) predicted from the in silico libraries used to query the As-PCF LC-MS/MS data. (B) Pooled As-PCF (P As-PCF) derived from female nematodes has a richer neuropeptide complement than single worm As-PCF samples (SW AsPCF) [54 peptides detected in pooled As-PCF $(n=17)$ vs an average of $17.75 \pm 1.2$ peptides across single worm samples $(n=20)]$. (C) The frequency of detection of individual peptides is variable in As-PCF. Dotted line represents detection rate in $50 \%$ of samples. Nine peptides are detected consistently in $>50 \%$ of As-PCF samples [As-Cecropin P1, As-Cecropin P2, As-FLP-18A, As-Cecropin P3, As-Defensin 2, As-Defensin 1, As-Nemapore 1, As-GRSP-16, As-Cecropin 6]. See File S2 for all peptide sequences detected. (D) Mass spectra of (i) FLP-18A detected in As-PCF (GFGDEMSMPGVLR) and (ii) As-FLP-18A isotopic standard (GFGDEMSMPGVLRF- $\mathrm{NH}_{2}$ ). Amino acid alignments indicate similar fragmentation patterns for As-FLP-18A detected in As-PCF and As-FLP-18A isotopic standard but that As-PCF-derived As-FLP-18A is truncated at the C-terminus. All data are represented as the mean \pm SEM.

Harnessing the chemotherapeutic potential of this system is undermined by a lack of knowledge on aspects of nematode neuropeptide signaling including those beyond the synaptic connectome. Indeed, the capability and characteristics of neuropeptide EVT in nematodes remain unreported, likely due to the lack of appropriate experimental and analytical tools for the investigation of extracellular communication via body fluid in model nematodes species including C. elegans. 
Table 1. High Confidence Peptides (>1\% FDR) Detected by LC-MS/MS in Ascaris suum PCF ${ }^{a}$

\begin{tabular}{|c|c|c|c|c|c|c|}
\hline Peptide Name & Peptide Sequence Predicted & Peptide Sequence Detected & $\begin{array}{l}\text { Cov. } \\
\%\end{array}$ & $\begin{array}{l}\text { Conf. } \\
-10 \lg P\end{array}$ & $\begin{array}{l}\text { Sample } \\
\%\end{array}$ & Sex \\
\hline As-FLP-18A & GFGDEMSMPGVLRF & $\begin{array}{l}\text { (A) GFGDEMSMPGVLR's } \\
\text { (B) (GFGDEM(+15.99)SMPGVLR) }\end{array}$ & 93 & $88.71^{\text {s }}$ & 92 & $\mathrm{~F}, \mathrm{M}$ \\
\hline As-NLP-20D1 & EMQFAFEEPSVDAERFARFA & $\begin{array}{l}\text { (A) AFEEPSVDAER } \\
\text { (B) FEEPSVDAER }\end{array}$ & 55 & $\begin{array}{l}92.71^{\circ} \\
60.76^{\varsigma}\end{array}$ & 21 & $\mathrm{~F}, \mathrm{M}$ \\
\hline As-NLP-40C & SWSTKEQVLQAIE & SVVSTKEQVLQ & 79 & 45.32 & 21 & $\mathbf{F}$ \\
\hline As-NLP-42C & $\begin{array}{l}\text { ALGGSVSPQWESSGWTWGE } \\
\text { QTFPLQESHTQRALRVAMT }\end{array}$ & E(-18.01)QTFP(-.98) & 13 & 71.58 & 46 & $\mathrm{~F}$ \\
\hline $\begin{array}{l}\text { As-Cecropin-1 } \\
\text { (P1) }\end{array}$ & $\begin{array}{l}\text { SWLSKTAKKLENSAKKRISEG } \\
\text { IAIAIQGGPR }\end{array}$ & SWLSKTAKKLENSAKKRISEGIAIAIQGGPR'S & 100 & $\begin{array}{l}309.6^{*} \\
182.2^{s}\end{array}$ & 100 & $\mathrm{~F}, \mathrm{M}$ \\
\hline $\begin{array}{l}\text { As-Cecropin-2 } \\
\text { (P2) }\end{array}$ & $\begin{array}{l}\text { SWLSKTYKKLENSAKKRISEG } \\
\text { IAIAIQGGPR }\end{array}$ & SWLSKTYKKLENSAKKRISEGIAIAIQGGPR`S & 100 & $\begin{array}{l}290.1^{\circ} \\
154.2^{s}\end{array}$ & 96 & $\mathrm{~F}, \mathrm{M}$ \\
\hline $\begin{array}{l}\text { As-Cecropin-3 } \\
\text { (P3) }\end{array}$ & $\begin{array}{l}\text { SWLSKTAKKLENSAKKRISEG } \\
\text { IAIAIKGGSR }\end{array}$ & SWLSKTAKKLENSAKKRISEGIAIAIKGGS'\$ & 97 & $\begin{array}{l}210.5^{\circ} \\
125.0^{s}\end{array}$ & 87.5 & $\mathrm{~F}, \mathrm{M}$ \\
\hline $\begin{array}{l}\text { As-Defensin-1 } \\
\text { (ASABF-6Cysa) }\end{array}$ & $\begin{array}{l}\text { NPQSTMDNSEDHNVKRDLCN } \\
\text { GRCKRMKCVLGASCKQRSG } \\
\text { QWVCVCKRPKDVMIKN }\end{array}$ & $\begin{array}{l}\text { (A) P.Q(-17.03)STMDNSEDHNVK } \\
\text { (B (P.Q(-17.03)STM(+15.99)DNSEDHNVK) } \\
\text { (C) Q(-17.03)STMDNSEDHNVK }\end{array}$ & 24 & $\begin{array}{l}191.6^{*} \\
134.8^{s}\end{array}$ & 79 & $\mathrm{~F}, \mathrm{M}$ \\
\hline $\begin{array}{l}\text { As-Defensin-2 } \\
\text { (ASABF-a) }\end{array}$ & $\begin{array}{l}\text { AVDFSSCARMDVPGLSKVAQ } \\
\text { GLCISSCKFQNCGTGHCEKR } \\
\text { GGRPTCVCDRCGRGGGEWP } \\
\text { SVPMPKGRSSRG }\end{array}$ & $\begin{array}{l}\text { (A) GGGEWPSVPMPKGRSSRG } \\
\text { (B) (Q(-17.03)GLCISS }(-.98)(+79.96))\end{array}$ & 35 & 271.4 & 88 & $\mathrm{~F}$ \\
\hline As-Defensin-14 & $\begin{array}{l}\text { GCPQHHVCNKHCLKLHGSRG } \\
\text { YCGGEDSRSCTCGMLFDY }\end{array}$ & LHGSRGY & 18 & 67.96 & 17 & $\mathbf{F}$ \\
\hline
\end{tabular}

$a_{*}$ Denotes data derived from female PCF samples. ${ }^{\$}$ Denotes data derived from male PCF samples. Cov. \% denotes percentage peptide detected. Conf. -10lgP, denotes confidence in peptides detected. Sample \% denotes the percentage of samples that peptides were detected in. F denotes female. $\mathrm{M}$ denotes male.

The zoonotic gastrointestinal parasite A. suum offers a unique opportunity to probe extrasynaptic communication in nematodes. Adult A. suum, which are up to $30 \mathrm{~cm}$ in length, contain body cavity fluid (pseudocoelomic fluid, As-PCF) that maintains hydrostatic pressure, bathes internal organs and muscle systems, and provides an ideal vehicle for non-neuronal communication. In contrast to $C$. elegans, the size of adult $A$. suum facilitates routine collection of relatively large volumes $(\sim 500 \mu \mathrm{L} /$ nematode $)$ of body cavity fluid for bioanalysis. This, in conjunction with the experimental tractability of Ascaris where tissues and organs can be readily dissected for physiology studies (see ref 20), offers a unique opportunity to investigate EVT in nematodes.

This study exploits peptidomics, nematode physiology, behavioral bioassays, heterologous expression, and bioinformatics approaches to investigate a role for nematode body cavity fluid in EVT of neuropeptides. We show that As-PCF contains a complex array of neuropeptides that modulate nematode behavior. Specifically, we demonstrate that (i) neuropeptides in As-PCF include FMRFamide-like peptides (FLPs) and neuropeptide-like proteins (NLPs), (ii) As-FLP18A (GFGDEMSMPGVLRF) is the dominant neuropeptide in As-PCF, (iii) As-PCF is bioactive on the reproductive muscle, altering activity ex vivo in a manner similar to that of synthetic As-FLP-18A, (iv) As-PCF activates the C. elegans FLP-18 receptors NPR-4 and -5 heterologously expressed in mammalian cells, (v) As-PCF and synthetic As-FLP-18A impact C. elegans behavior, and (vi) FLP-18 and the cognate receptors NPR-4 and -5 display pan-distribution across phylum Nematoda.

This study suggests that neuropeptide signaling may be mediated non-neuronally by EVT in nematodes. These novel data add a new dimension to the interpretation of spatial and functional information pertaining to the nematode nervous system.

\section{RESULTS AND DISCUSSION}

Ascaris PCF Contains a Rich Peptide Library. Liquid chromatography coupled with mass spectrometric (LC-MS/ MS) analyses of As-PCF [total of $n=24$ LC-MS/MS runs analyzing As-PCF from 67 worms: $n=20$ single female worms, $20 \mathrm{LC}-\mathrm{MS} / \mathrm{MS}$ runs; pooled adult female As-PCF $(n=17$ worms), one LC-MS/MS run; pooled adult male As-PCF ( $n$ $=18, n=6, n=6$ worms), 3 LC-MS/MS runs; see File S1] reveals that multiple peptide families are present in nematode body cavity fluid. We queried the As-PCF peptidome with $A$. suum in silico peptide libraries (unpublished, constructed inhouse; see File S1) for the major nematode neuropeptide families [FLPs and neuropeptide-like proteins (NLPs)], as well as antimicrobial peptides (AMPs). We detected 76 peptides in As-PCF of adult nematodes [41 neuropeptides (6 FLPs, 35 NLPs and 35 AMPs; see Figure $1 \mathrm{~A}$ and File S2)]. Highconfidence peptide spectrum matches ( $1 \%$ FDR) were confirmed for 10 peptides $^{22}$ (see Table 1 ).

Our experimental approach involved peptidome analyses of single ( $n=20$ worms; 20 LC-MS/MS runs) and pooled adult female ( $n=17$ worms; one LC-MS/MS run) and pooled adult male As-PCF (3 LC-MS/MS runs: $n=18, n=6, n=6$, worms, respectively). This strategy enabled comparison of both pooled and single-worm As-PCF samples in addition to sex differences. Pooled As-PCF revealed a richer peptide complement than single As-PCF samples; 54 peptides were detected in the pooled sample ( $n=17$ female worms) relative to $17.75 \pm 1.2$ peptides detected in single worm samples $(n=$ 20 worms) (Figure 1B). Six peptides were detected in the pooled sample that were not identified from single worm samples (As-FLP-18D, As-FLP-18E, As-NLP-14N, As-NLP66B, As-GRSP-2, and As-NLP-14K; see File S2). These data indicate that, while pooled samples reveal As-PCF peptidome complexity, single worm As-PCF characterization also has utility as an experimental platform for the interrogation of key peptides which are consistently detected in individual worms (see $1 \%$ FDR peptides, Table 1 and File S2). In addition, these 
A

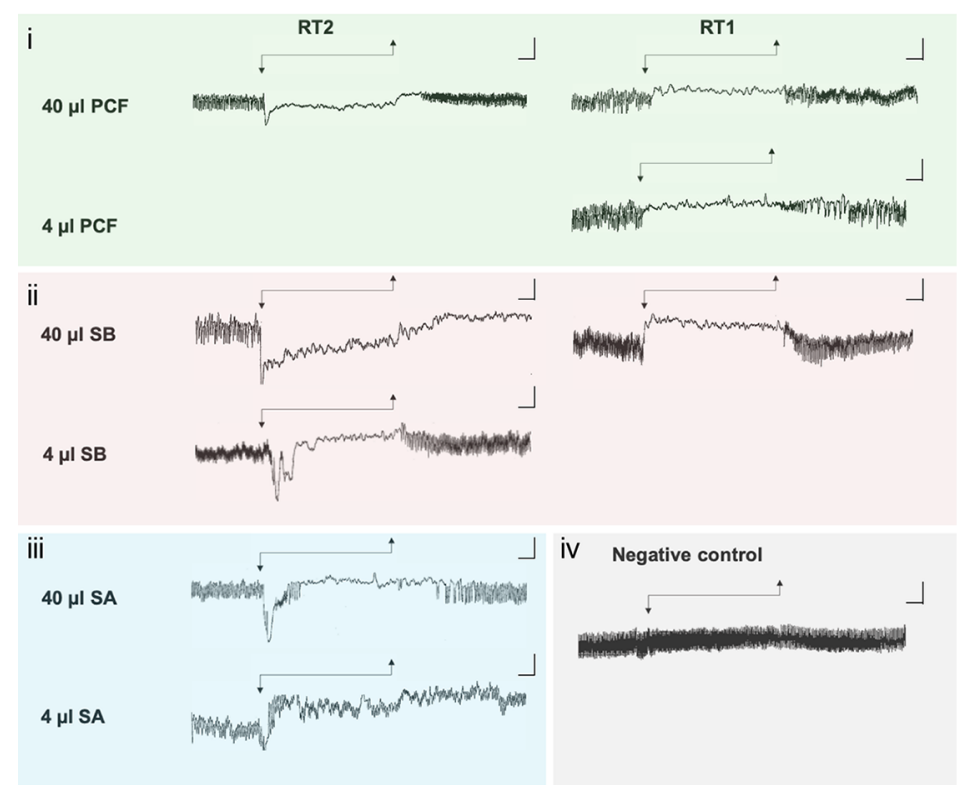

C

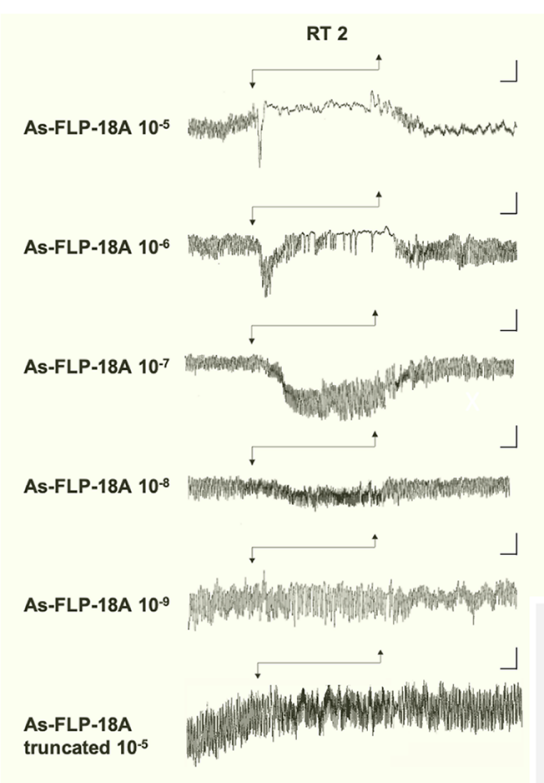

B
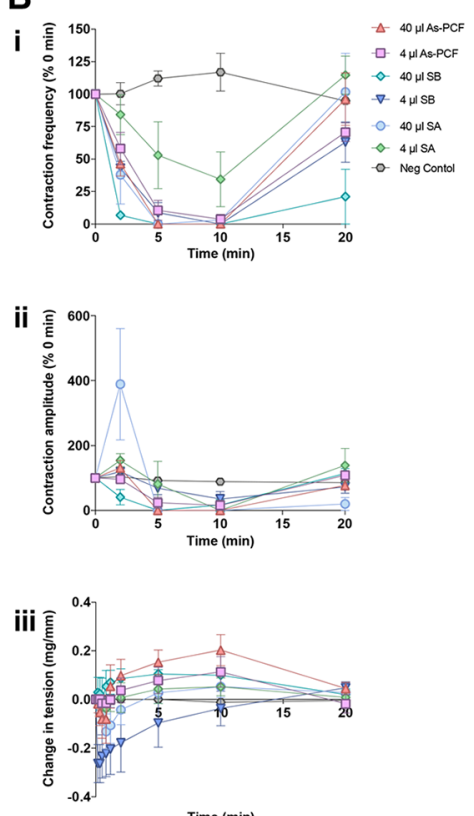

D
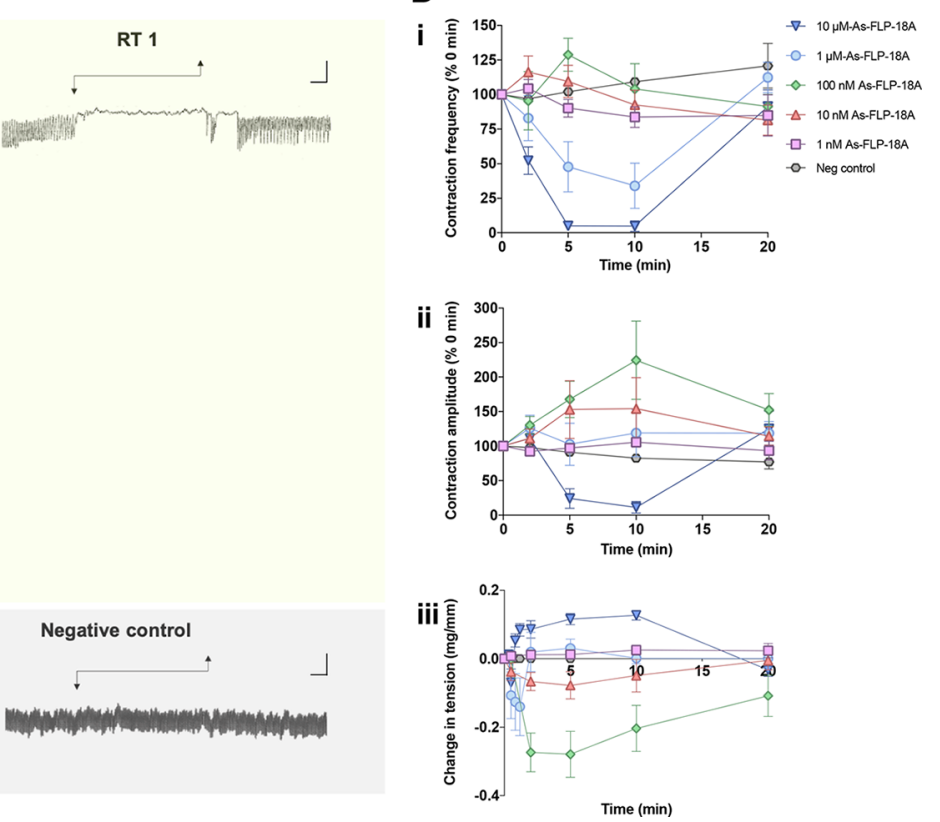

Figure 2. Ascaris suum pseudocoelomic fluid (As-PCF) is bioactive on Ascaris ovijector tissue and mirrors the synthetic As-FLP-18A peptide response. (A) Representative muscle tension recordings showing the effects of As-PCF on A. suum ovijector tissue: (i) As-PCF induces two distinct, concentration dependent, myoactivity profiles (known as response types; RT) on the A. suum ovijector; $40 \mu \mathrm{L}$ of As-PCF (equivalent to $\geq 0.15 \times$ As-PCF where $1 \times$ is representative of the biological sample) induces either a transient muscle contraction followed by muscle paralysis (50\% of preparations; RT-2) or immediate muscle relaxation (50\% of preparations; RT-1). $4 \mu \mathrm{L}$ of As-PCF (equivalent to $0.015 \times$ As-PCF where $1 \times$ is representative of the biological sample) induces an RT-1 response only. (ii) Positive controls [phosphate buffered saline spiked with synthetic AsFLP-18A (GFGDEMSMPGVLRF-NH ${ }_{2}$ ) before $\mathrm{C} 18$ peptide purification; SB] induce two distinct, concentration dependent myoactivity profiles on the A. suum ovijector. $40 \mu \mathrm{L}$ of SB (equivalent to final concentration of $1 \mu \mathrm{M}$ synthetic As-FLP-18A) induces either a RT-2 (50\% of preparations) or RT-1 (50\% of preparations) response. $4 \mu \mathrm{L}$ of SB (equivalent to final concentration of $0.1 \mu \mathrm{M}$ synthetic As-FLP-18A) induces an RT-2 response only. (iii) Positive controls [phosphate buffered saline spiked with synthetic As-FLP-18A (GFGDEMSMPGVLRF-NH ${ }_{2}$ after C18 peptide purification (SA) also induced a concentration dependent myoactivity profile on the A. suum ovijector. $40 \mu \mathrm{L}$ and $4 \mu \mathrm{L}$ of SA controls (equivalent to final concentration of $1 \mu \mathrm{M}$ and $100 \mathrm{nM}$ synthetic As-FLP-18A, respectively) induce an RT-2 response in 100\% of preparations. (iv) Negative control (perfused activation solution only resuspended in $\mathrm{ddH}_{2} \mathrm{O}$ ) does not modulate intrinsic ovijector contractility. Test compounds (As-PCF, SB, SA, negative control) were present during the period indicated by arrows. Vertical scales represent $2 \mathrm{mg}$, and horizontal scales represent 2 min. (B) Effects of As-PCF and positive controls (SB and SA) on (i) contraction frequency, (ii) contraction amplitude, and (iii) muscle tension of the A. suum ovijector. Test compounds (As-PCF, SB, or SA) were added at 0 min and washed out at 10 min. Data are presented as the mean \pm SEM (see Table S1). (C) Representative muscle tension recordings showing the effects of synthetic As-FLP-18A on A. suum ovijector tissue. $1 \mathrm{nM}$ to $10 \mu \mathrm{M}$ synthetic As-FLP-18A induce concentration dependent myoexcitatory effects. $10 \mu \mathrm{M}$ synthetic As-FLP-18A induces two 
Figure 2. continued

distinct myoexcitatory profiles consistent with RT-2 (35.7\% of preparations) or RT-1 (64.2\% of preparations). $1 \mu \mathrm{M}$ to $10 \mathrm{nM}$ synthetic As-FLP18A induce RT-2 responses only. The truncated form of synthetic As-FLP-18A (GFGDEMSMPGVLR; $10 \mu \mathrm{M}$ ) does not modulate ovijector contractility. Negative control $\left(\mathrm{dd}_{2} \mathrm{O}\right)$ does not modulate intrinsic ovijector contractility. Peptide was present during the period indicated by the arrows. Vertical scales represent $2 \mathrm{mg}$ and horizontal scales represent $2 \mathrm{~min}$. (D) Concentration dependent effects of $1 \mathrm{nM}$ to $10 \mu \mathrm{M}$ synthetic AsFLP-18A on (i) contraction frequency, (ii) contraction amplitude, and (iii) muscle tension of the A. suum ovijector. Peptide was added at 0 min and washed out at $10 \mathrm{~min}$. All data are presented as the mean \pm SEM (see Table S2).

data also suggest that in single worm samples some peptides may be present at lower concentrations, nearing the limit of LC/MS detection. Male and female As-PCF comparisons revealed two peptides that were male As-PCF specific: AsNLP-43C and a novel FLP, As-FLP-35 (ANTATASWSIEWLMRL-NH $\mathrm{N}_{2}$; see File S2). As-FLP-35 is a novel FLP recently predicted from the $A$. suum genome ${ }^{23}$ (data unpublished).

Antimicrobial peptides were the most abundant family of peptides detected in the As-PCF (97\% of AMP library predictions); As-Cecropin-1 and -2 also known as P1 and $\mathrm{P} 2$, respectively; ${ }^{24}$ were the most highly detected peptides in $>96 \%$ of samples at $>97 \%$ coverage (Figure 1A,C and Table 1). FLPs and NLPs displayed greater variability in both the frequency of detection and overall peptide coverage. However, most strikingly, As-FLP-18A equaled the frequency and coverage of the AMPs, highlighting that this is the dominant neuropeptide in the As-PCF peptidome (detected in 92\% of samples at $>93 \%$ coverage; Figure 1A,C and File S2). While the number of NLPs detected was greater than the number of FLPs, the majority were low frequency (where approximately half of NLPs were detected only once) with the exception of As-NLP-21G and As-NLP-42C (detected in $42 \%$ and $46 \%$ of samples, respectively; see Figure $1 \mathrm{~A}-\mathrm{D}$ and File S2).

This is the first direct experimental demonstration of neuropeptides in nematode body cavity fluid. This discovery supports hypotheses on extrasynaptic small molecule neurotransmitter signaling via body cavity fluid in C. elegans ${ }^{15,18}$ and represents a step-change in the understanding of nematode neuronal signaling such that EVT should be considered in the interpretation and comprehension of nematode neurobiology.

As-PCF Neuropeptidome Data Support Caenorhabditis elegans Neurobiology. Neuropeptides are released into the body cavity fluid of invertebrates where they act as neurohormones to regulate many physiological functions. ${ }^{25} \mathrm{~A}$ number of the peptides consistently detected in As-PCF in this study (FLP-18, NLP-21, -37, -40) have been reported in C. elegans in cells that link them to the PCF. For example NLP$21,-37$, and -40 have been localized to C. elegans coelomocytes, which have roles in the endocytosis of secreted proteins from the PCF; ${ }^{11,12,26,27}$ this has also been observed for additional neuropeptides, e.g., INS-22, ${ }^{26}$ that were not included in the custom peptide library used to probe the As-PCF peptidome in this study. Due to their localization in coelomocyte scavenger cells, it has been postulated that these peptides are released from dense core vesicles into the pseudocoelomic fluid and endocytosed. However, until now, their presence in nematode PCF has not been substantiated. In addition, C. elegans NLP37 (PDF-2) has been assigned a long-range neuromodulatory function via release into the $\mathrm{PCF}^{28-30}$ as also observed for a PDF homologue in locust. ${ }^{31}$ The detection of NLP-37 in AsPCF provides evidence for a conserved neuromodulatory role in nematodes. Significantly, a neuromodulatory/neurohormonal role for FLP-18 has also previously been suggested in C. elegans, $^{32}$ where localization data revealed a physical disconnect between neurons expressing FLP-18 and the location of FLP18 cognate receptors. The consistent presence of As-FLP-18A in the As-PCF peptidome confirms the potential for FLP-18 peptides to modulate neurobiology via EVT in nematodes including A. suum and C. elegans.

A role for neuropeptide EVT in body cavity fluid has been hypothesized for both $A$. suum and C. elegans. 9,14,19,32 However, the novel As-PCF data presented here demonstrate that AsPCF has a restricted peptidome relative to the predicted (in silico) whole worm peptidome, consistent with selective release of bioactive peptides into this compartment.

As-FLP-18A Dominates the Ascaris PCF Neuropeptidome. As-flp-18 encodes six peptides that share a common Cterminal PGVLRF-NH $\mathbf{H}_{2}$ motif (As-FLP-18A, GFGDEMSMPGVLRF-NH ${ }_{2}$; As-FLP-18B, GMPGVLRF$\mathrm{NH}_{2} ;$ As-FLP-18C, AVPGVLRF-NH ${ }_{2}$; As-FLP-18D, GDVPGVLRF-NH ${ }_{2}$; As-FLP-18E, SDMPGVLRF-NH ${ }_{2}$;As-

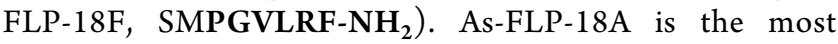
frequently detected neuropeptide in As-PCF (92\% of samples, $>93 \%$ coverage; Figure 1C), which leads us to hypothesize that As-FLP-18 peptides play an important role in the A. suum PCF.

In our LC/MS analysis, we consistently detected a truncated form of As-FLP-18A (GFGDEMSMPGVLR; see Figure 1D) lacking the $\mathrm{C}$-terminal phenylalanine-amide motif required for biological activity (see Figure 2C). While the detection of a truncated peptide could be an artefact of sample processing, we attempted to minimize this possibility as As-PCF was collected and processed rapidly and shipped under temperaturecontrolled conditions to limit proteolytic degradation. Enhanced detection of truncated As-FLP-18A could be a result of more-ready ionization of the arginine residue (position -1) in comparison to the intact As-FLP-18A (Cterminal phenylalanine-amide motif). Interestingly, in the pooled As-PCF samples we also detected As-FLP-18D and As-FLP-18E in addition to As-FLP-18A. In these samples, AsFLP-18D and E were also detected in the truncated form without the expected C-terminal phenylalanine-amide motif. Detection of these additional As-FLP peptides in pooled samples, but not in individual worm As-PCF, suggests that these peptides are present at lower concentrations, nearing the LC/MS limit of detection. An alternative hypothesis is that the truncated forms of As-FLP-18A, D, and E are produced postinteraction with As-FLP-18 receptors in a signal termination event. Indeed, the $\mathrm{E} / \mathrm{S}$ products and PCF of nematodes including A. suum are known to be peptidase-rich and include a range of cysteine proteases. ${ }^{33-36}$ These peptidases may be selectively released at the target receptor to spatiotemporally control peptide interactions and mediate neuropeptide action. ${ }^{37}$ In this scenario, peptidase action could manifest in an elevation, and thus an enhanced detection, of truncated versus intact As-FLP-18 peptides. This is consistent with our observations and would contribute to the plasticity of nematode neuronal signaling via EVT. The biological reason 
for the predominance of As-FLP-18A over the additional five peptides encoded by As-flp-18 is unclear. Indeed, As-flp-18 is not predicted to be differentially spliced in A. suum as revealed by both genome-level analyses and molecular (PCR) investigation (data not shown). Regardless, truncated AsFLP-18A (synthetic) lacks biological activity in A. suum muscle physiology assays in contrast to intact As-FLP-18A (synthetic) and As-PCF, which both induce characteristic FLP-18 responses (see subsequent discussion and Figure 2A-D). These data suggest that both the intact and truncated form of As-FLP-18A may be present in As-PCF.

The Bioactivity of Ascaris PCF on Ascaris Reproductive Tissue Mirrors That of Synthetic As-FLP-18A. Neuropeptides potently modulate the intrinsic muscle activity of Ascaris reproductive organs (ovijector) ${ }^{38-43}$ defined by five distinct response types (RT-1-RT-5), ranging from inhibition of muscle contraction (flaccid paralysis, e.g., RT-1) to increased contraction frequency (e.g. RT5). ${ }^{39}$

As-PCF also potently modulates Ascaris reproductive muscle activity. Exogenously applied As-PCF induces two distinct myoactivity profiles on the ovijector that are characteristic of either an RT-1- or RT-2-like response ${ }^{39}$ (see Figure 2A,B). At low concentrations $[0.015 \times$ As-PCF (where $1 \times$ As-PCF represents the native biological sample)], As-PCF consistently inhibits muscle activity in an RT-1-like response (Figure 2A,B; Table S1). At higher concentrations $(\geq 0.15 \times$ As-PCF), the response profile included both RT-1 (inhibitory; $50 \%$ of preparations) and RT-2-like responses (excitatory; 50\% of preparations) (see Figure 2A,B; Table S1). All effects were reversible upon As-PCF washout.

Interestingly, in this study we present myoactivity profiles for As-PCF that are consistent with the myoactivity profile of synthetic As-FLP-18A which is also the amidated form of the dominant As-PCF neuropeptide. Synthetic As-FLP-18A induces consistent excitatory effects $(10 \mathrm{nM}$ to $1 \mu \mathrm{M})$ that include transient muscle contraction followed by muscle paralysis ( $1 \mu \mathrm{M}$; RT-2-like; Figure 2C,D; Table S2). ${ }^{39}$ At high concentrations $(10 \mu \mathrm{M})$ synthetic As-FLP-18A induces two distinct myoexcitatory profiles that resemble those observed with high concentrations of As-PCF (RT-1-like, $64.2 \%$ of preparations; RT-2-like, $35.7 \%$ of preparations; see Figure 2C,D and Table S2). These responses were corroborated in synthetic peptide positive controls subjected to the same experimental manipulations as As-PCF (Figure 2A; Table S2).

As-FLP-18 peptides (PGVLRF-NH $\mathrm{N}_{2}$ ) have been implicated in locomotion, feeding, and reproductive function via whole worm, pharyngeal, and ovijector tissue bioassays; see ref 20 . However, although $A s-f l p-18$ encoded peptides are potent stimulators of the Ascaris ovijector, their expression patterns appear to be limited to neurons that are anatomically distinct from, and have no known synaptic connections to, reproductive tissue as demonstrated by in situ hybridization and MS/MS. ${ }^{44,45}$ The ovijector receives input from two parallel neuronal cell bodies situated in close proximity to the body wall and the ventral nerve cord (similar positions to $C$. elegans VC4 and VC5). ${ }^{38}$ In another study, RNAseq analysis was conducted on two distinct tissue types: (i) the gonopore region, an area of body wall tissue that contains the neuronal cell bodies that innervate the ovijector, and (ii) the ovijector itself which expresses the postsynaptic receptors. Our tissuespecific differential expression analyses of As-flp-18 and the AsFLP-18 cognate GPCR sequelogs As-npr-4 and As-npr-5 $5^{13,32,46}$ revealed that the neuronal cell bodies innervating the ovijector do not express As-flp-18 despite the presence of both cognate receptors in the ovijector tissue (see Figure S3). These data support the hypothesis that As-PCF-circulating neuropeptides modulate $A$. suum reproductive function. While our data point toward a significant role for As-FLP-18A in modulating reproductive function via EVT, the contribution of other peptides detected in the As-PCF will require further investigation to unravel EVT dynamics.

Ascaris PCF Activates Heterologously Expressed Caenorhabditis elegans NPR-4 and NPR-5. To characterize the interaction of As-PCF with the cognate FLP-18 receptors NPR-4 and -5 and to provide further evidence for As-FLP-18 signaling via EVT, we measured the response of Ce-NPR-4 and -5 [expressed in Chinese hamster ovary $(\mathrm{CHO})$ cells] to AsPCF and synthetic As-FLP-18 peptides. Note that attempts to express As-NPR-4 and -5 in the heterologous $\mathrm{CHO}$ system were unsuccessful in this study consistent with difficulties in parasitic nematode GPCR heterologous expression, ${ }^{20}$ requiring the use of the C. elegans receptors as surrogates. As-PCF and synthetic As-FLP-18 peptides potently activated Ce-NPR-4 and -5 (synthetic Ce-FLP-18 peptides also elicited the expected responses; see Figure 3A-C). Synthetic As-FLP18A-E elicited significant $\mathrm{Ca}^{2+}$ responses in cells transfected with C. elegans NPR-4 and cells transfected with NPR-5, compared to the negative control (cell medium without peptide; see Figure 3A). Synthetic As-FLP-18 peptides did not evoke significant $\mathrm{Ca}^{2+}$ responses in $\mathrm{CHO}$ cells transfected with an empty vector, confirming that Ce-NPR-4 and -5 mediate the observed physiological responses (Figure 3A). As-PCF also evoked a significant $\mathrm{Ca}^{2+}$ response in Ce-NPR-4 or Ce-NPR-5 transfected cells compared to negative controls (see Figure 3B,C). A low-level $\mathrm{Ca}^{2+}$ response was observed in cells transfected with an empty control vector as well, indicating that some component(s) of As-PCF interact with receptors endogenously expressed in $\mathrm{CHO}$ cells (see Figure 3B,C). Despite this, As-PCF elicited a significantly higher response in cells expressing Ce-NPR-4 or -5 than the negative control (empty vector transfected $\mathrm{CHO}$ cells), indicating that a significant component of the As-PCF response is specific to Ce-NPR-4 and -5 activation (see Figure $3 \mathrm{~B}$ and Figure 3C, respectively).

The activation of heterologously expressed Ce-NPR-4 and -5 by As-PCF and synthetic As-FLP-18 peptides suggests conservation of the FLP-18 interaction with NPR-4 and $-5^{32,46}$ in Ascaris and supports our hypothesis that As-PCF peptides interact with putative FLP-18 receptors in vivo via EVT.

Ascaris PCF Impacts Caenorhabditis elegans Growth and Locomotion. To further investigate the biological activity of As-PCF in nematodes, we examined the effects of As-PCF and synthetic As-FLP-18A in C. elegans using two behavioral assays that assess nematode growth (body length) and motility (locomotory activity) $)^{47}$ in Ce-acs-20 cuticle defective mutant to facilitate peptide uptake. ${ }^{48}$ Caenorhabditis elegans growth was potently inhibited in a dose-dependent manner by $2 \%$ and $5 \%$ As-PCF; this effect was mirrored by treatment of $C$. elegans with the dominant As-PCF neuropeptide As-FLP-18A (100 $\mu \mathrm{M}$, synthetic peptide) (see Figure 4A). Caenorhabditis elegans motility was significantly impaired in the presence of 5, 7.5, and 10\% As-PCF as measured by the wMicroTracker (InVivo Biosystems, Oregon, USA); synthetic As-FLP-18A $(10 \mu \mathrm{M})$ also produced significant inhibition of 


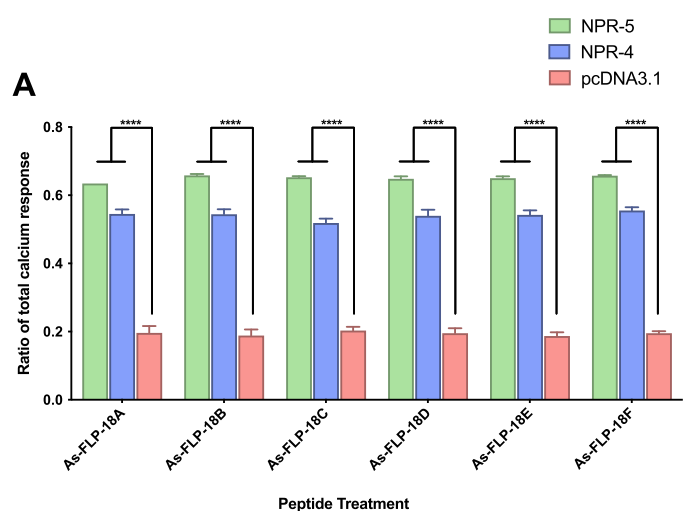

B
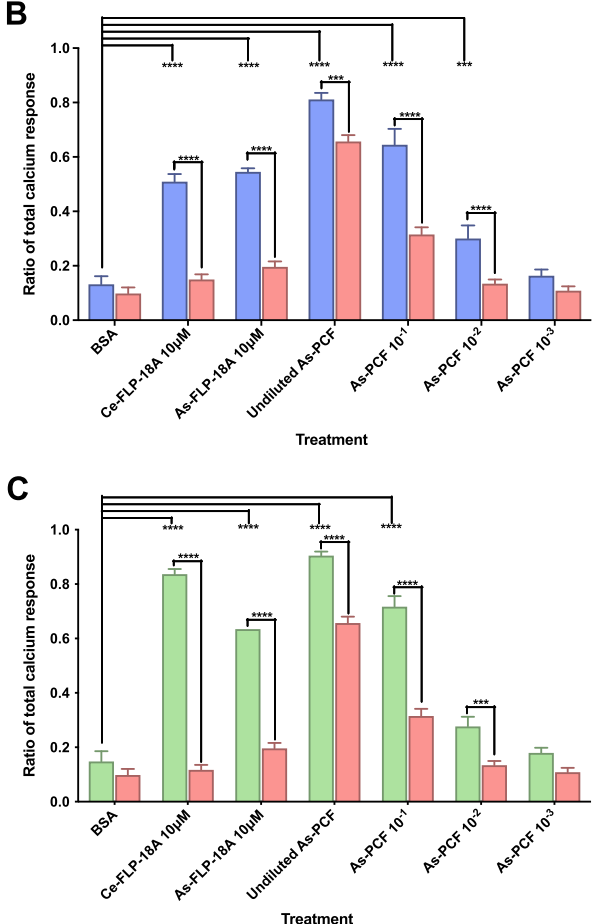

Figure 3. Ascaris suum PCF (As-PCF) activates heterologously expressed Caenorhabditis elegans neuropeptide receptors NPR-4 and NPR-5 in mammalian cell lines. (A) C. elegans NPR-4 (Ce-NPR-4) and -5 (Ce-NPR-5) expressed in $\mathrm{CHO}$ cells are activated by synthetic As-FLP-18 peptides (10 $\mu \mathrm{M}$; As-FLP-18A, GFGDEMSMPGVLRF$\mathrm{NH}_{2}$; As-FLP-18B, GMPGVLRF-NH $\mathrm{N}_{2}$; As-FLP-18C, AVPGVLRF$\mathrm{NH}_{2}$; As-FLP-18D, GDVPGVLRF-NH $\mathrm{N}_{2}$; As-FLP-18E, SDMPGVLRF-NH ${ }_{2}$; As-FLP-18F, SMPGVLRF- $\mathrm{NH}_{2}$ ) compared to controls transfected with an empty vector (pcDNA3.1). (B) Ce-NPR4 is activated by As-PCF in a concentration dependent manner compared to both peptide-free cell medium (BSA) and empty vector (pcDNA3.1) negative controls. The cognate Ce-NPR-4 peptide CeFLP-18A (DFDGAMPGVLRF-NH ${ }_{2}$ ) and As-FLP-18A were used as positive controls. (C) Ce-NPR-5 is also activated by As-PCF in a concentration dependent manner compared to both peptide-free cell medium (BSA) and empty vector (pcDNA3.1) negative controls. The cognate Ce-NPR-5 peptide Ce-FLP-18A and As-FLP-18A were used as positive controls. In all cases data are shown as the ratio of peptide/ As-PCF response to total calcium response. Error bars represent the mean \pm SEM, $n>3$ replicates. Statistical significance of peptide or AsPCF-evoked responses compared with BSA or empty vector controls was determined by two-way ANOVA and Tukey's multiple comparisons test. $P$-values are denoted by $* * *(<0.001)$ and $* * * *$ $(<0.0001)$.
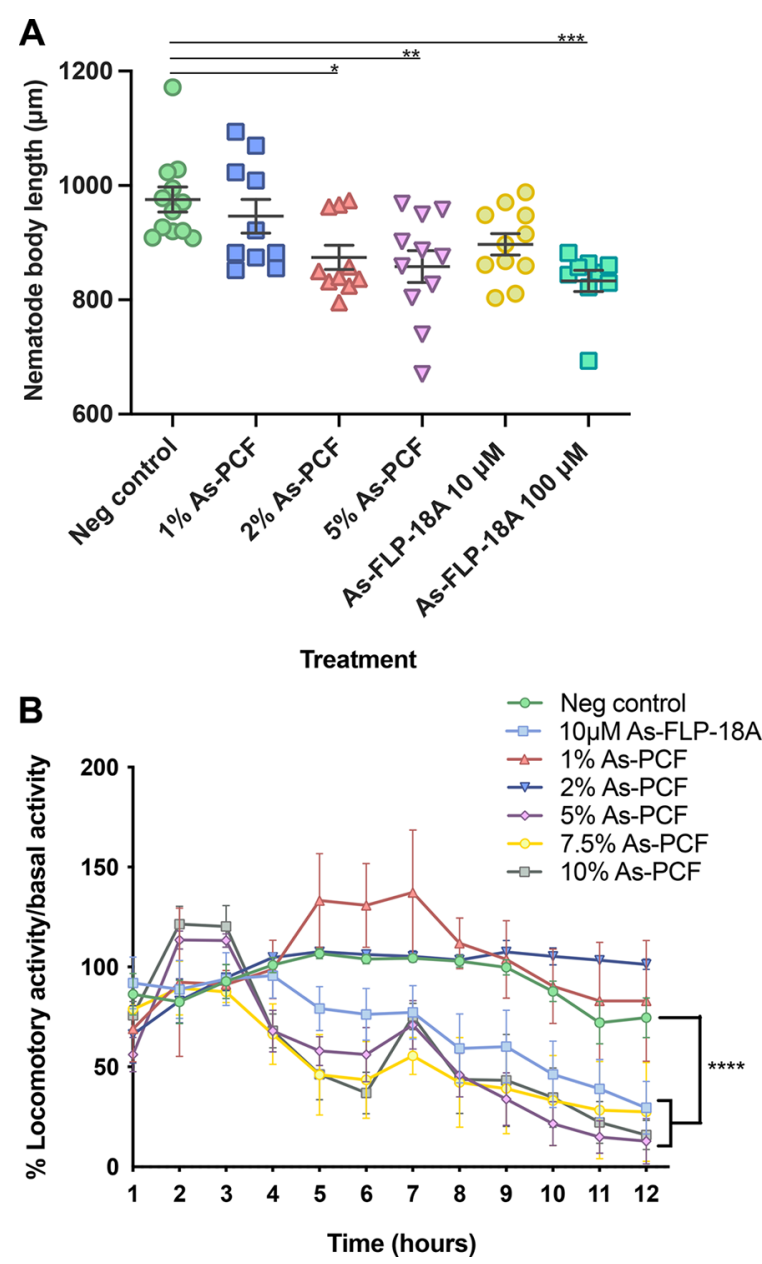

Figure 4. Exogenous application of Ascaris suum PCF (As-PCF) and synthetic As-FLP-18A influences Caenorhabditis elegans growth and motility. (A) C. elegans growth (as measured by changes in body length) is significantly reduced in nematodes exposed to $2 \%$ and $5 \%$ As-PCF and $100 \mu \mathrm{M}$ synthetic As-FLP-18A (GFGDEMSMPGVLRF$\mathrm{NH}_{2}$ ) compared to the negative control (nematodes exposed to $\mathrm{S}$ medium only). (B) C. elegans motility (as measured locomotory activity over time) is significantly reduced in nematodes exposed to $5 \%, 7.5 \%, 10 \%$ As-PCF and $10 \mu \mathrm{M}$ synthetic As-FLP-18A compared to the negative control (nematodes exposed to M9 only). Statistical significance is determined by one-way ANOVA and Dunnett's multiple comparisons test (A) or two-way ANOVA and Tukey's multiple comparisons test (B). $P$-values are denoted by $*(<0.05)$, ** $(<0.01), * * *(<0.001)$, and $* * * *(<0.0001)$.

locomotion (see Figure 4B). In all assays the As-PCF induced modulation of $C$. elegans behavior was consistent with that observed for the synthetic As-FLP-18A peptide (see Figure $4 A, B)$ and corresponds to published literature which demonstrates the modulatory activity of FLP-18 in a number of C. elegans behaviors and biological processes. ${ }^{49}$

flp-18 and the Cognate Receptors, npr-4 and npr-5, Display Pan-Phylum Conservation in Nematodes. In silico analyses of 134 available nematode genomes (see Figure S2), representing 109 species, 7 clades, and 3 distinct lifestyles (free-living, animal parasitic, and plant parasitic), ${ }^{50-52}$ demonstrate striking flp-18 pan-phylum conservation in $99 \%$ of nematode species [see Figure 5]. flp-18 is the only neuropeptide gene that displays this level of conservation in phylum Nematoda (unpublished data). These data drive the hypothesis that FLP-18 peptides are fundamental to nematode 


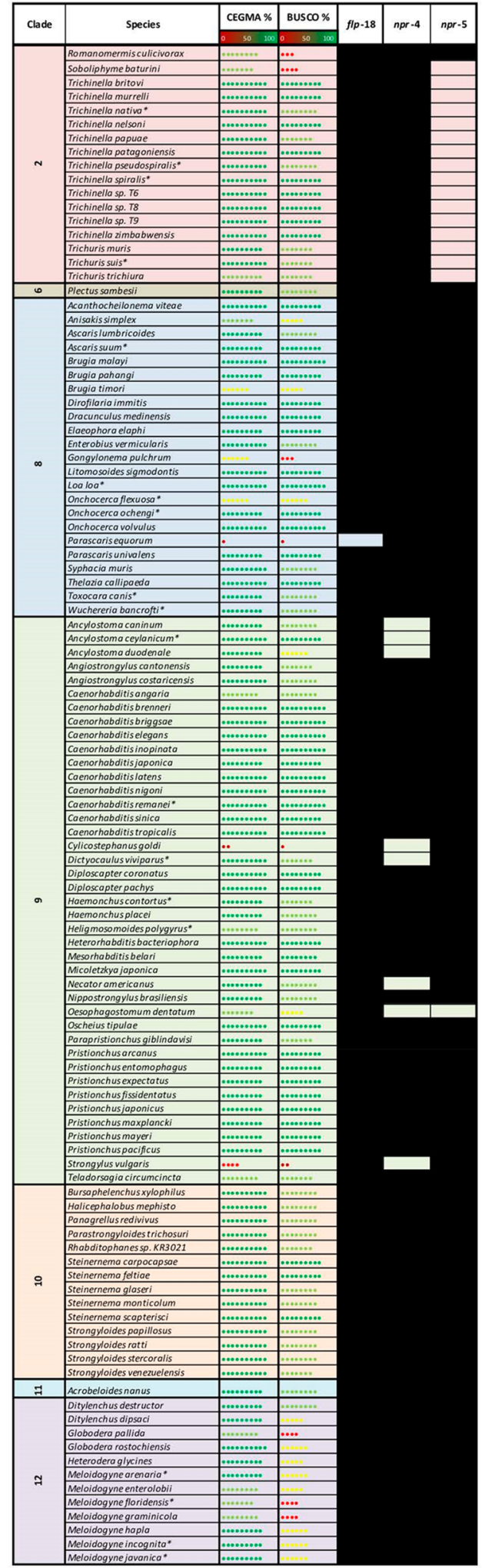

Figure 5. Caenorhabditis elegans flp-18 and the cognate FLP-GPCR encoding gene homologues $n p r-4$ and $n p r-5$ display pan-phylum conservation in nematodes. Pan-phylum HMM analysis of 134 nematode genomes (109 species) demonstrates that C. elegans flp-18, $n p r-4$, and $n p r-5$ encoding gene homologues are highly conserved (99\%, 93\%, 84\%, respectively) in nematodes. Black boxes indicate the presence of a putative gene homologue. Presence/absence identified based on motif conservation and reciprocal BLAST. Nematode species are arranged based on 12 clade designation. ${ }^{53}$ Asterisk denotes
Figure 5. continued

that multiple genomes were mined per species. Genome quality is indicated by CEGMA and BUSCO scores obtained from Wormbase Parasite version $14 .^{50-52,54,55}$ A list of genomes mined, HMM query sequences returned, and retrieved gene homologues are detailed in File S3.

biology and support the potential for FLP-18 signaling via EVT to be a pan-phylum trait.

Broad conservation was also noted for the putative FLP-18 receptor encoding genes ( $n p r-4$ in $93 \%$ of species and $n p r-5$ in $84 \%$ of species; see Figure 5), highlighting their importance across phylum Nematoda. It is interesting to note that for most of the species examined (98\%), the presence of the FLP-18encoding gene was indicative of the presence of either putative cognate receptor or both and vice versa (Figure 5). These data suggest that the FLP-18-NPR-4/5 interaction, which has been functionally validated in C. elegans, Brugia malayi, ${ }^{32,46}$ and in this study, $A$. suum, is highly conserved across nematodes; consequently these receptors hold significant appeal as broadspectrum drug targets in parasitic nematodes.

\section{CONCLUSIONS}

This study reveals a rich neuropeptide profile in the body cavity fluid of a parasitic nematode and, for the first time, provides direct evidence indicating that EVT is an integral part of the nematode functional connectome. These data demonstrate that nematode signaling systems operate within a connectome comprising both wired and wireless components, adding complexity and plasticity to nematode communication frameworks. The biological significance and potential for chemotherapeutic exploitation of the nematode connectome are significantly enhanced by the wireless data presented here. The combined network infrastructure revealed by the experimental tractability of $A$. suum in this study provides a unique and powerful tool to unravel the intricacies of information flow within the nervous system of nematodes and higher organisms.

\section{METHODS}

Collection and Maintenance of Ascaris suum. Adult A. suum samples were collected at a local abattoir (Karro Food Group Ltd., Cookstown, Northern Ireland), transported to the laboratory in saline $(0.9 \% \mathrm{NaCl})$, and maintained in Ascaris Ringers Solution (ARS: 13.14 $\mathrm{mM} \mathrm{NaCl}, 9.47 \mathrm{mM} \mathrm{CaCl}_{2}, 7.83 \mathrm{mM} \mathrm{MgCl}, 12.09 \mathrm{mM} \mathrm{C}_{4} \mathrm{H}_{11} \mathrm{NO}_{3} /$ Tris, $99.96 \mathrm{mM} \mathrm{NaC}_{2} \mathrm{H}_{3} \mathrm{O}_{2}, 19.64 \mathrm{mM} \mathrm{KCl}, \mathrm{pH} 7.8$ ) at $37^{\circ} \mathrm{C}$ until use.

Maintenance of Caenorhabditis elegans. The C. elegans cuticle defective mutant strain acs-20 tm $3232^{48}$ was obtained from the National BioResource Project of the Tokyo Women's Medical University (Tokyo, Japan). Ce-acs-20 have defects in the cuticle barrier which increase permeability to small molecules. ${ }^{48}$ Ce-acs-20 were maintained on Nematode Growth Media (NGM) plates seeded with Escherichia coli OP50 (CGC) and synchronized using established methods, prior to all experiments. ${ }^{56,57}$ Young adult stage C. elegans were used in all experiments.

Ascaris suum Pseudocoelomic Fluid Collection. As-PCF collection from adult A. suum was carried out within $3 \mathrm{~h}$ of parasite collection. Female worms $>20 \mathrm{~cm}$ were used in experiments. Between 400 and $1000 \mu \mathrm{L}$ of As-PCF was collected from each female worm, and between 100 and $500 \mu \mathrm{L}$ of As-PCF was collected from each male worm. As-PCF was obtained from blot-dried (Kimwipes, Fisher Scientific, U.K.) female worms by holding the specimen vertically above a $2 \mathrm{~mL}$ low binding microcentrifuge tube (Fisher Scientific, 
U.K.) and carefully snipping $<3 \mathrm{~mm}$ tissue from the tail (posterior to the anal pore and the major ganglia) using a pair of sterile scissors. AS-PCF was discharged from the worm into the collection tube with the aid of internal turgor pressure and gentle manual compression. Male As-PCF was collected by drying the cuticle and making a $1 \mathrm{~cm}$ incision with a sharp scalpel approximately $5 \mathrm{~cm}$ posterior to the head (mid-body region) and allowing turgor pressure to discharge As-PCF into a $2 \mathrm{~mL}$ collection tube; male worms are not amenable to female worm As-PCF collection processes due to the close proximity of male reproductive organs at the posterior tip of the tail which prevents access to the pseudocoelomic cavity. As-PCF was placed on ice immediately after collection. Single worm As-PCF $(n=24)$ and pooled As-PCF analyses ( $n=17$ worms pooled) were conducted for female worms. Male single worm As-PCF analysis was not possible due to the low volume of As-PCF retrieved from individual male worms; As-PCF collected from 30 males was used in pooled analyses

LC-MS/MS. Peptide Extraction: Peptide extraction was carried out in two stages. Phase 1 was conducted at Queen's University Belfast immediately following As-PCF collection; phase 2 was conducted at the University of Wisconsin-Madison, WI, USA.

Phase 1: As-PCF was spiked with an equal volume of acidified methanol $\left(90 \% \mathrm{MeOH}, 9 \% \mathrm{ddH}_{2} \mathrm{O}, 1 \%\right.$ glacial $\left.\mathrm{CH}_{3} \mathrm{COOH}\right)$ immediately following collection (to extract peptides and precipitate large proteins), vortexed, and centrifuged for $15 \mathrm{~min}$ at $20000 \mathrm{~g}$. The supernatant was retained in a $2 \mathrm{~mL}$ low binding microcentrifuge tube (Fisher Scientific, U.K.). The pellet was resuspended in $500 \mu \mathrm{L}$ of acidified methanol using a sterile plastic pestle. This was repeated twice more, and the supernatant from each extraction was retained as above in addition to the final pellet. $250 \mu \mathrm{L}$ of $\mathrm{ddH}_{2} \mathrm{O}$ was added to the supernatant solutions from extractions 2 and 3 to decrease $\mathrm{MeOH}$ concentration to $60 \%$. All three supernatant solutions and the final pelleted solids remaining after the third extraction were snap frozen in liquid $\mathrm{N}_{2}$ and stored at $-80{ }^{\circ} \mathrm{C}$ prior to shipping.

Phase 2: Upon receipt (University of Wisconsin-Madison), frozen supernatant was thawed and loaded immediately onto a $10 \mathrm{kDa}$ molecular weight cutoff membrane (Sigma-Aldrich, St. Louis, MO) which was rinsed with $0.1 \mathrm{M} \mathrm{NaOH}$ and $50 / 50 \mathrm{MeOH} / \mathrm{H}_{2} \mathrm{O},(\mathrm{v} / \mathrm{v})$ prior to sample loading. The tube holding the membrane was centrifuged at $14000 \mathrm{~g}$ for $10 \mathrm{~min}$, and the filtrate was dried in a SpeedVac concentrator (Thermo Fisher Scientific, Waltham, MA, USA). The purified sample was resuspended in $150 \mu \mathrm{L}$ of $0.1 \%$ formic acid (FA) in $\mathrm{H}_{2} \mathrm{O}$, desalted by OMIX $\mathrm{C} 18$ pipet tips (Agilent Technologies, Santa Clara, CA), and finally eluted into $0.1 \%$ FA in $50 / 50 \mathrm{ACN} / \mathrm{H}_{2} \mathrm{O}(\mathrm{v} / \mathrm{v})$. The eluate was concentrated until dry and stored at $-80{ }^{\circ} \mathrm{C}$.

LC-MS/MS Analysis: Stored samples were dissolved in $10 \mu \mathrm{L}$ of $0.1 \%$ formic acid (FA). Nano-LC-MS/MS analysis was carried out using a Waters Nano-Acquity Ultra Performance LC system (Waters Corp, Milford, MA, USA) coupled to a Q-Exactive Quadrupole Orbitrap mass spectrometer (Thermo Scientific Bremen, Germany). A self-packed column ( $150 \mathrm{~mm}$ length of $1.7 \mu \mathrm{m} \mathrm{C18}$ with a $3 \mu \mathrm{m}$ C18 cap) was used for chromatographic separation. The mobile phase involved in online separation was the following: $A, 0.1 \%$ FA in $\mathrm{H}_{2} \mathrm{O}$ and $\mathrm{B}, 0.1 \% \mathrm{FA}$ in ACN. A 120 min gradient was applied at flow rate of $0.3 \mu \mathrm{L} / \mathrm{min}$, starting from $100 \% \mathrm{~A}$. Mobile phase B increased to $10 \%$ in $1 \mathrm{~min}, 35 \%$ at $90 \mathrm{~min}, 95 \%$ at $92 \mathrm{~min}$. The gradient remained at $5 \% \mathrm{~A}$ for $10 \mathrm{~min}$, then recovered to $100 \% \mathrm{~A}$ at $105 \mathrm{~min}$. Data were collected under positive electrospray ionization (ESI) data-dependent mode (DDA), with the top 15 abundant precursor ions selected for HCD fragmentation with listed settings: full-MS, resolution, 70000 ; automatic gain control (AGC), $1 \times 10^{6}$; scan range, $\mathrm{m} / z$ 200-2000; dd-MS2, resolution 17500 ; AGC, $2 \times 10^{5}$; isolation window, $\mathrm{m} / \mathrm{z} 2.0$; fixed first mass, $\mathrm{m} / z$ 100.0; normalized collision energy, 30 . Other typical MS parameters were the following: spray voltage, $2.1 \mathrm{kV}$; no sheath and auxiliary gas flow; heated capillary temperature, $275^{\circ} \mathrm{C}$.

MS Data Analysis: Parent mass error tolerance was $10 \mathrm{ppm}$, and fragment mass error tolerance was $0.02 \mathrm{Da}$. C-terminal amidation, methionine oxidation, and pyroglutamation were specified as variable post-translational modification (PTMs). No enzyme cleavage was selected within the de novo sequencing. A custom neuropeptide database representing predicted A. suum FLPs, NLPs, and AMPs was used in the search process. The peptide database was compiled via a comprehensive in silico analysis of the predicted protein data sets derived from the published $A$. suum genomes ${ }^{23,58,59}$ following established methods. ${ }^{60,61}$ A threshold of false discovery rate (FDR) of $1 \%$ was used for data filtration and validation. NanoLC-ESI-MS raw data were analyzed by PEAKS Studio 7 (Bioinformatics Solution Inc., Waterloo, ON, Canada).

Ascaris suum Ovijector Bioassays. Tissue Excision and Data Collection: Adult female A. suum ovijector tissue and data collection was carried out as previously described. ${ }^{42}$ Briefly, freshly excised $A$. suum ovijector tissue was attached to the recording apparatus and synthetic peptide or As-PCF was added directly to the chamber following tissue equilibration. Muscle activity was recorded for 10 $\mathrm{min}$. Media in the recording chamber were then replaced with fresh HBSS $\left(37^{\circ} \mathrm{C}\right.$; Sigma-Aldrich), and the muscle was allowed to recover for a further $10 \mathrm{~min}$. If regular baseline activity was achieved following washout, further experiments with the specimen were conducted.

FLP-18 Bioassays: A. suum synthetic FLP-18 peptide [As-FLP-18A, GFGDEMSMPGVLRFNH ${ }_{2}$; Genosphere Biotechnologies (France)] was tested for bioactivity on ovijector tissue. Peptide stock solutions $(10 \mathrm{mM}$ to $1 \mu \mathrm{M})$ were prepared using $\mathrm{ddH}_{2} \mathrm{O}$ such that $4 \mu \mathrm{L}$ of peptide stock solution was added to $4 \mathrm{~mL}$ of HBSS in the recording chamber to achieve the desired final peptide concentration (10-0.001 $\mu \mathrm{M}) . \mathrm{ddH}_{2} \mathrm{O}$ was used as a negative control.

As-PCF Bioassays: $3 \mathrm{~mL}$ of fresh As-PCF was collected from female worms (as described above) and passed through a Sep-Pak Classic C18 cartridge (Waters, Ireland). Sep-Pak Classic C18 cartridges were activated with $3 \mathrm{~mL}$ of activation solution $(3 \mathrm{~mL}$ of ultrapure acetonitrile, 0.1\% HPLC grade trifluoroacetic acid) and washed with 6

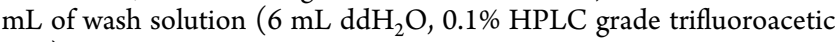
acid). Following initial flow through, As-PCF effluent was passed through the $\mathrm{C} 18$ cartridge twice more to ensure optimal peptide binding. C18 cartridges were then washed using $6 \mathrm{~mL}$ of wash solution, and peptides were eluted in $3 \mathrm{~mL}$ of activation solution. All samples were dried overnight using a GenevacMiVac concentrator at $37{ }^{\circ} \mathrm{C}$ and stored at $4{ }^{\circ} \mathrm{C}$ until use. Samples were resuspended in 200 $\mu \mathrm{L}$ of $\mathrm{ddH}_{2} \mathrm{O}$ immediately before use. Controls included phosphate buffered saline (PBS; $150 \mathrm{mM} \mathrm{NaCl}, 0.025 \mathrm{M} \mathrm{NaH}_{2} \mathrm{PO}_{4} \cdot 2 \mathrm{H}_{2} \mathrm{O}, 0.075$ $\mathrm{M} \mathrm{Na}_{2} \mathrm{HPO}_{4}, \mathrm{pH}$ 7.4) spiked with synthetic As-FLP-18A (PBS-AsFLP-18 SB; $100 \mu \mathrm{M}$ ) before C18 perfusion, PBS spiked with synthetic As-FLP-18A after C18 perfusion (PBS-As-FLP-18 SA; $100 \mu \mathrm{M}$ ), and perfused activation solution only (resuspended in $\mathrm{ddH}_{2} \mathrm{O}$; negative control); SB controls for the $\mathrm{C} 18$ processing event, whereas SA controls for the overnight drying process. 4 or $40 \mu \mathrm{L}$ of As-PCF [15X concentrated; final concentration in recording chamber $0.015 \times$ and $0.15 \times$ As-PCF, respectively (where $1 \times$ As-PCF represents the native biological sample)], PBS-As-FLP-18 SB (final concentration in recording chamber $0.1 \mu \mathrm{M}$ or $1 \mu \mathrm{M}$ ), or PBS-As-FLP-18 SA (final concentration in recording chamber $0.1 \mu \mathrm{M}$ or $1 \mu \mathrm{M}$ ) was added to the recording chamber $(n=4)$, and effects on ovijector muscle were recorded. All data were analyzed as described. ${ }^{42}$ Statistical analyses included repeated measures ANOVA and Student's $t$-test to assess the significance of test substance/peptide effects and effect reversal after washout, respectively (see Tables S1 and S2; Alpha 0.05).

Cell-Culture Activation Assays for Caenorhabditis elegans Receptors. GPCR activation assay was performed as previously described. ${ }^{17,62}$ Briefly, mammalian CHO K1 cells stably overexpressing apoaequorin and human $\mathrm{G} \alpha_{16}$ (ES-000-A24, PerkinElmer) were transiently transfected with Ce-npr-4a/pcDNA3.1, Ce-npr-5a/ pcDNA3.1, or empty pcDNA3.1 (negative control) plasmid using Lipofectamine LTX and Plus reagent (Invitrogen, U.K.). After transfection, cells were grown in culture flasks overnight at $37^{\circ} \mathrm{C}$, after which they were transferred to $28^{\circ} \mathrm{C}$ and allowed to incubate for $24 \mathrm{~h}$. On the day of the assay, $\mathrm{CHO}$ cells were harvested and loaded with coelenterazine $\mathrm{H}$ (Invitrogen) for $4 \mathrm{~h}$ at room temperature, which elicits the formation of the $\mathrm{Ca}^{2+}$-sensitive photoprotein aequorin. As-PCF or synthetic peptides (As-FLP-18 or Ce-FLP-18) dissolved in DMEM/BSA medium were added to cells, and luminescence was measured for $30 \mathrm{~s}$ at $496 \mathrm{~nm}$ using a Mithras 
LB940 luminometer (Berthold Technologies, Germany). After $30 \mathrm{~s}$ of readout, $0.1 \%$ Triton $\mathrm{X}-100$ was added to lyse the cells, resulting in a maximal $\mathrm{Ca}^{2+}$ response that was measured for $10 \mathrm{~s}$. Note that $C$. elegans synthetic peptides were synthesized by Thermo Scientific and A. suum synthetic peptides were synthesized by Genosphere Biotechnologies (France). All peptides were tested at a final concentration of $10 \mu \mathrm{M}$. The final concentration of As-PCF was half the concentration of the undiluted sample. In addition, a 10 -fold dilution series ranging from $1 / 20$ to $1 / 2000$ of the undiluted As-PCF sample was tested. Assays were performed in triplicate on at least two different days. Data were analyzed using GraphPad Prism version 8. Statistical significance was determined by one-way ANOVA and Dunnett's multiple comparisons test or two-way ANOVA and Tukey's multiple comparisons test $($ Alpha $=0.05)$.

Caenorhabditis elegans Bioassays. Body Length Assay: C. elegans body size assays were carried out as previously described. ${ }^{47}$ Nematodes were treated with either 1, 2, or 5\% As-PCF [diluted in Smedium, $1 \mathrm{~L}$ of $\mathrm{S}$ Basal, $10 \mathrm{~mL}$ of $1 \mathrm{M}$ potassium citrate, $\mathrm{pH}$ 6.0, 10 $\mathrm{mL}$ of trace metals solution, $3 \mathrm{~mL}$ of $1 \mathrm{M} \mathrm{CaCl}_{2}, 3 \mathrm{~mL}$ of $1 \mathrm{M}$ $\left.\mathrm{MgSO}_{4}\right)^{56}$ ], $10 \mu \mathrm{M}$ synthetic As-FLP-18A [positive control; Genosphere Biotechnologies (France)] or S-medium (negative control; $n>$ 9 nematodes per treatment). Following incubation at $20{ }^{\circ} \mathrm{C}$ for $96 \mathrm{~h}$ nematodes were immobilized in M9 buffer containing $50 \mathrm{mM}$ sodium azide $\left(\mathrm{NaN}_{3}\right)$ and body length was calculated using a Leica MZ 12.5 stereomicroscope, Unibrain Fire-i digital camera, and ImageJ software. ${ }^{63}$

wMicroTracker Motility Assay: 50 C. elegans in M9 buffer were added to each well of a 96-well plate along with E. coli OP50 $\left(\mathrm{OD}_{600 \mathrm{~nm}}\right.$ of 1$)$ to a final volume of $90 \mu \mathrm{L}$. Basal locomotory activity was recorded for $1 \mathrm{~h}$ using the wMicroTracker (InVivo Biosystems, Oregon, USA) with a bin size of $30 \mathrm{~min}$. After $1 \mathrm{~h}$ each well was supplemented with $10 \mu \mathrm{L}$ of $1,2,5,7.5$, or $10 \%$ As-PCF (diluted in M9), M9 buffer (negative control), or $10 \mu \mathrm{M}$ synthetic As-FLP-18A (positive control) ( $n>4$ wells/treatment). Nematode locomotory activity was recorded for a further $12 \mathrm{~h}$. Data were analyzed using GraphPad Prism version 8. Statistical significance was determined by one-way ANOVA and Dunnett's multiple comparisons test or twoway ANOVA and Tukey's multiple comparisons test $($ Alpha $=0.05)$.

In Silico Identification of $\mathrm{flp}-18, n p r-4$, and -5 . Putative nematode $f l p-18, n p r-4$, and $n p r-5$ orthologs were identified from WormBase ParaSite version 14, https://parasite.wormbase.org/index. html; ${ }^{50-52}$ and aligned using CLUSTAL Omega default settings. ${ }^{64}$ Alignments were subsequently used to construct Hidden Markov Models (HMM) using HMMER v3.2 default hmmbuild parameters, ${ }^{65}$ based on methods previously described. ${ }^{66}$ hmmsearch (default settings) was employed to identify potential $f l p-18, n p r-4$, and $n p r-5$ sequences within the predicted protein data sets of 109 nematode species 134 genomes; see File S2. ${ }^{52}$ The putative $n p r-4$ and -5 sequences identified via hmmsearch were then used as queries in reciprocal BLASTp searches in the NCBI nonredundant $C$. elegans predicted protein database (https://blast.ncbi.nlm.nih.gov; default settings). The putative $f l p-18$ sequences identified via hmmsearch were confirmed visually via the presence of the conserved PGXXRFG C-terminal motif (see Figure S1). Queries that failed to return a putative target gene as the highest scoring pair/top hit were excluded from downstream analyses. Genomes lacking putative target gene hits were subjected to manual BLASTp and tBLASTn using WormBase ParaSite version 14 and C. elegans flp-18, npr-4, and $n p r-5$ as query sequences. Additionally, orthologs from the most closely related nematode species were also used as queries in BLASTp/tBLASTn searches.

\section{ASSOCIATED CONTENT}

\section{SI Supporting Information}

The Supporting Information is available free of charge at https://pubs.acs.org/doi/10.1021/acschemneuro.1c00281.

Table S1 listing the modulatory effects of As-PCF on Ascaris suum ovijector tissue preparations; Table S2 listing the modulatory effects of synthetic As-FLP-18A on Ascaris suum ovijector tissue preparations; Figure S1 showing the alignment of FMRF-amide-like peptide 18 (FLP-18) sequelogues; Figure S2 showing supplementary references for all genomes used in this study; Figure S3 showing differential expression of As-flp-18 and As$n p r-4$ and -5 in Ascaris body wall and ovijector tissue (PDF)

File S1 containing the custom Ascaris suum in silico peptide library of predicted $A$. suum FLPs, NLPs and AMPs used in this study, including gene IDs, prepropeptide sequences, predicted peptides, and predicted peptide masses (XLSX)

File S2 containing As-PCF peptides detected in this study, including high confidence peptides ( $>1 \%$ FDR) detected across all samples (Table 1 ; tab 1 ), peptides detected in single female samples (Table 2; tab 2), peptides detected in pooled female samples (Table 3; tab 3), peptides detected in pooled male samples (Table 4 ; tab 4$) ;-10 \lg P$ denotes $P$-value $\left[-10 \log _{10}(P\right.$-value $\left.)\right]$ as converted by PEAKS software (XLSX)

File S3 containing nematode genomes mined for gene sequelogues of $f l p-18, n p r-4$, and $n p r-5^{50-52}$ including gene IDs for each identified sequelogue (XLSX)

\section{AUTHOR INFORMATION}

\section{Corresponding Author}

Angela Mousley - Microbes and Pathogen Biology, The Institute for Global Food Security, School of Biological Sciences, Queen's University Belfast, Belfast BT9 5DL, U.K.; ○ orcid.org/0000-0001-7373-912X; Email: a.mousley@ qub.ac.uk

\section{Authors}

Louise E. Atkinson - Microbes and Pathogen Biology, The Institute for Global Food Security, School of Biological Sciences, Queen's University Belfast, Belfast BT9 5DL, U.K.; (1) orcid.org/0000-0002-5184-2676

Yang Liu - School of Pharmacy and Department of Chemistry, University of Wisconsin-Madison, Madison, Wisconsin 53705, United States

Fiona McKay - Microbes and Pathogen Biology, The Institute for Global Food Security, School of Biological Sciences, Queen's University Belfast, Belfast BT9 5DL, U.K.

Elke Vandewyer - Department of Biology, KU Leuven, 3000 Leuven, Belgium

Charles Viau - Microbes and Pathogen Biology, The Institute for Global Food Security, School of Biological Sciences, Queen's University Belfast, Belfast BT9 5DL, U.K.

Allister Irvine - Microbes and Pathogen Biology, The Institute for Global Food Security, School of Biological Sciences, Queen's University Belfast, Belfast BT9 5DL, U.K.

Bruce A. Rosa - McDonnell Genome Institute, and Division of Infectious Diseases, Department of Medicine, Washington University School of Medicine, St. Louis, Missouri 63108, United States

Zihui Li - School of Pharmacy and Department of Chemistry, University of Wisconsin-Madison, Madison, Wisconsin 53705, United States

Qingxiao Liang - Microbes and Pathogen Biology, The Institute for Global Food Security, School of Biological Sciences, Queen's University Belfast, Belfast BT9 5DL, U.K. 
Nikki J. Marks - Microbes and Pathogen Biology, The Institute for Global Food Security, School of Biological Sciences, Queen's University Belfast, Belfast BT9 5DL, U.K.

Aaron G. Maule - Microbes and Pathogen Biology, The Institute for Global Food Security, School of Biological Sciences, Queen's University Belfast, Belfast BT9 5DL, U.K.

Makedonka Mitreva - McDonnell Genome Institute, and Division of Infectious Diseases, Department of Medicine, Washington University School of Medicine, St. Louis, Missouri 63108, United States

Isabel Beets - Department of Biology, KU Leuven, 3000 Leuven, Belgium

Lingjun Li - School of Pharmacy and Department of Chemistry, University of Wisconsin-Madison, Madison, Wisconsin 53705, United States; 10 orcid.org/0000-00030056-3869

Complete contact information is available at:

https://pubs.acs.org/10.1021/acschemneuro.1c00281

\section{Author Contributions}

A.M. provided funding and resources, designed the study, conducted experiments, analyzed data, and wrote the manuscript. L.E.A. designed the study, conducted experiments, analyzed data, and wrote the manuscript. Y.L., F.M., E.V., C.V., A.I., B.A.R., and Z.L. conducted experiments and analyzed data. I.B., L.L., and M.M. provided resources and methodological expertise. N.J.M. and A.G.M. provided funding, designed the study, and reviewed and edited the manuscript.

\section{Funding}

The authors acknowledge support for this work from Biotechnology and Biological Sciences Research Council New Investigator Grant BB/H019472/1 (A.M.); Biotechnology and Biological Sciences Research Council/Boehringer Ingelheim Grant BB/MO10392/1 (A.M., N.J.M., and A.G.M.); Biotechnology and Biological Sciences Research Council/Boehringer Ingelheim Grant BB/TO16396/1 (A.M., N.J.M., A.G.M., L.E.A.); Department for Economy Northern Ireland (DfE) Studentship (F.M.); Department of Agriculture Environment and Rural Affairs Northern Ireland (DAERA) Studentship (A.I.); National Institutes of Health (NIH, USA) Grant GM097435 (M.M.); National Institutes of Health (NIH, USA) Grants R01DK071801 and S10RR029531 (L.L.); Research Foundation Flanders (FWO) Grant G0C0618N (I.B.).

\section{Notes}

The authors declare no competing financial interest.

\section{ACKNOWLEDGMENTS}

The authors thank Dr. Brett Greer for technical assistance/ equipment and Sorcha Donnelly for assistance with As-PCF collection. The authors are grateful to Karro, Cookstown, Northern Ireland, for the assistance in the collection of nematodes.

\section{REFERENCES}

(1) White, J. G., Southgate, E., Thomson, J. N., and Brenner, S. (1986) The structure of the nervous system of the nematode Caenorhabditis elegans. Philos. Trans. R. Soc. London B 314, 1-340.

(2) Cook, S. J., Jarrell, T. A., Brittin, C. A., Wang, Y., Bloniarz, A. E., Yakovlev, M. A., Nguyen, K. C. Q., Tang, L. T., Bayer, E. A., Duerr, J. S., Bulow, H. E., Hobert, O., Hall, D. H., and Emmons, S. W. (2019) Whole-animal connectomes of both Caenorhabditis elegans sexes. Nature 571, 63-71.
(3) Albertson, D. G., and Thomson, J. N. (1976) The pharynx of Caenorhabditis elegans. Philos. Trans. R. Soc. London B 275, 299-325.

(4) Stretton, A. O. W., and Maule, A. G. (2013) The Neurobiology of Ascaris and Other Parasitic Nematodes. In Ascaris: The Neglected Parasite (Holland, C., Ed.) Chapter 6, pp 127-152, Elsevier, Amsterdam.

(5) Bargmann, C. I. (2012) Beyond the connectome: how neuromodulators shape neural circuits. BioEssays 34, 458-465.

(6) Brezina, V. (2010) Beyond the wiring diagram: signalling through complex neuromodulator networks. Philos. Trans. R. Soc., B $365,2363-2374$

(7) Liang, Z., Schmerberg, C. M., and Li, L. (2015) Mass spectrometric measurement of neuropeptide secretion in the crab, Cancer borealis, by in vivo microdialysis. Analyst 140, 3803-3813.

(8) Jekely, G., Melzer, S., Beets, I., Kadow, I. C. G., Koene, J., Haddad, S., and Holden-Dye, L. (2018) The long and the short of it-a perspective on peptidergic regulation of circuits and behaviour. J. Exp. Biol. 221, jeb166710.

(9) Smart, D., Shaw, C., Johnston, C. F., Halton, D. W., Fairweather, I., and Buchanan, K. D. (1992) Chromatographic and immunological characterisation of neuropeptide Y-like and pancreatic polypeptidelike peptides from the nematode Ascaris suum. Comp. Biochem. Physiol., C: Comp. Pharmacol. 102, 477-481.

(10) Laurent, P., Ch'ng, Q., Jospin, M., Chen, C., Lorenzo, R., and de Bono, M. (2018) Genetic dissection of neuropeptide cell biology at high and low activity in a defined sensory neuron. Proc. Natl. Acad. Sci. U. S. A. 115, E6890-e6899.

(11) Wang, H., Girskis, K., Janssen, T., Chan, J. P., Dasgupta, K., Knowles, J. A., Schoofs, L., and Sieburth, D. (2013) Neuropeptide secreted from a pacemaker activates neurons to control a rhythmic behavior. Curr. Biol. 23, 746-754.

(12) Sieburth, D., Madison, J. M., and Kaplan, J. M. (2007) PKC-1 regulates secretion of neuropeptides. Nat. Neurosci. 10, 49-57.

(13) Rogers, C., Reale, V., Kim, K., Chatwin, H., Li, C., Evans, P., and de Bono, M. (2003) Inhibition of Caenorhabditis elegans social feeding by FMRFamide-related peptide activation of NPR-1. Nat. Neurosci. 6, 1178-1185.

(14) Komuniecki, R., Hapiak, V., Harris, G., and Bamber, B. (2014) Context-dependent modulation reconfigures interactive sensorymediated microcircuits in Caenorhabditis elegans. Curr. Opin. Neurobiol. 29, 17-24.

(15) Chase, D. L., and Koelle, M. R. (2007) Biogenic amine neurotransmitters in C. elegans, pp 1-15, WormBook.

(16) Chew, Y. L., Tanizawa, Y., Cho, Y., Zhao, B., Yu, A. J., Ardiel, E. L., Rabinowitch, I., Bai, J., Rankin, C. H., Lu, H., Beets, I., and Schafer, W. R. (2018) An Afferent Neuropeptide System Transmits Mechanosensory Signals Triggering Sensitization and Arousal in C. elegans. Neuron 99, 1233-1246.

(17) Beets, I., Janssen, T., Meelkop, E., Temmerman, L., Suetens, N., Rademakers, S., Jansen, G., and Schoofs, L. (2012) Vasopressin/ oxytocin-related signaling regulates gustatory associative learning in C. elegans. Science 338, 543-545.

(18) Chase, D. L., Pepper, J. S., and Koelle, M. R. (2004) Mechanism of extrasynaptic dopamine signaling in Caenorhabditis elegans. Nat. Neurosci. 7, 1096-1103.

(19) Bentley, B., Branicky, R., Barnes, C. L., Chew, Y. L., Yemini, E., Bullmore, E. T., Vertes, P. E., and Schafer, W. R. (2016) The Multilayer Connectome of Caenorhabditis elegans. PLoS Comput. Biol. 12, No. e1005283.

(20) McCoy, C. J., Atkinson, L. E., Robb, E., Marks, N. J., Maule, A G., and Mousley, A. (2017) Tool-Driven Advances in Neuropeptide Research from a Nematode Parasite Perspective. Trends Parasitol. 33, 986-1002.

(21) McVeigh, P., Atkinson, L., Marks, N. J., Mousley, A., Dalzell, J. J., Sluder, A., Hammerland, L., and Maule, A. G. (2012) Parasite neuropeptide biology: Seeding rational drug target selection? Int. J. Parasitol.: Drugs Drug Resist. 2, 76-91.

(22) Zhang, J., Xin, L., Shan, B., Chen, W., Xie, M., Yuen, D., Zhang, W., Zhang, Z., Lajoie, G. A., and Ma, B. (2012) PEAKS DB: de novo 
sequencing assisted database search for sensitive and accurate peptide identification. Mol. Cell. Proteomics 11, M111.010587.

(23) Jex, A. R., Liu, S., Li, B., Young, N. D., Hall, R. S., Li, Y., Yang, L., Zeng, N., Xu, X., Xiong, Z., Chen, F., Wu, X., Zhang, G., Fang, X., Kang, Y., Anderson, G. A., Harris, T. W., Campbell, B. E., Vlaminck, J., Wang, T., Cantacessi, C., Schwarz, E. M., Ranganathan, S., Geldhof, P., Nejsum, P., Sternberg, P. W., Yang, H., Wang, J., Wang, J., and Gasser, R. B. (2011) Ascaris suum draft genome. Nature 479, 529533.

(24) Pillai, A., Ueno, S., Zhang, H., Lee, J. M., and Kato, Y. (2005) Cecropin P1 and novel nematode cecropins: a bacteria-inducible antimicrobial peptide family in the nematode Ascaris suum. Biochem. J. 390, 207-214.

(25) Nusbaum, M. P., Blitz, D. M., and Marder, E. (2017) Functional consequences of neuropeptide and small-molecule cotransmission. Nat. Rev. Neurosci. 18, 389-403.

(26) Ch'ng, Q., Sieburth, D., and Kaplan, J. M. (2008) Profiling synaptic proteins identifies regulators of insulin secretion and lifespan. PLoS Genet. 4, No. e1000283.

(27) Hao, Y., Hu, Z., Sieburth, D., and Kaplan, J. M. (2012) RIC-7 promotes neuropeptide secretion. PLoS Genet. 8, No. e1002464.

(28) Choi, S., Chatzigeorgiou, M., Taylor, K. P., Schafer, W. R., and Kaplan, J. M. (2013) Analysis of NPR-1 reveals a circuit mechanism for behavioral quiescence in C. elegans. Neuron 78, 869-880.

(29) Janssen, T., Husson, S. J., Lindemans, M., Mertens, I., Rademakers, S., Ver Donck, K., Geysen, J., Jansen, G., and Schoofs, L. (2008) Functional characterization of three G protein-coupled receptors for pigment dispersing factors in Caenorhabditis elegans. $J$. Biol. Chem. 283, 15241-15249.

(30) Janssen, T., Husson, S. J., Meelkop, E., Temmerman, L., Lindemans, M., Verstraelen, K., Rademakers, S., Mertens, I., Nitabach, M., Jansen, G., and Schoofs, L. (2009) Discovery and characterization of a conserved pigment dispersing factor-like neuropeptide pathway in Caenorhabditis elegans. J. Neurochem. 111, 228-241.

(31) Persson, M. G., Eklund, M. B., Dircksen, H., Muren, J. E., and Nassel, D. R. (2001) Pigment-dispersing factor in the locust abdominal ganglia may have roles as circulating neurohormone and central neuromodulator. J. Neurobiol. 48, 19-41.

(32) Cohen, M., Reale, V., Olofsson, B., Knights, A., Evans, P., and de Bono, M. (2009) Coordinated regulation of foraging and metabolism in C. elegans by RFamide neuropeptide signaling. Cell Metab. 9, 375-385.

(33) Rhoads, M. L., and Fetterer, R. H. (1998) Purification and characterisation of a secreted aminopeptidase from adult Ascaris suum. Int. J. Parasitol. 28, 1681-1690.

(34) Wang, T., Van Steendam, K., Dhaenens, M., Vlaminck, J., Deforce, D., Jex, A. R., Gasser, R. B., and Geldhof, P. (2013) Proteomic analysis of the excretory-secretory products from larval stages of Ascaris suum reveals high abundance of glycosyl hydrolases. PLoS Neglected Trop. Dis. 7, No. e2467.

(35) Chehayeb, J. F., Robertson, A. P., Martin, R. J., and Geary, T. G. (2014) Proteomic analysis of adult Ascaris suum fluid compartments and secretory products. PLoS Neglected Trop. Dis. 8, No. e2939.

(36) Rosa, B. A., Townsend, R., Jasmer, D. P., and Mitreva, M. (2015) Functional and phylogenetic characterization of proteins detected in various nematode intestinal compartments. Mol. Cell Proteomics 14, 812-827.

(37) Nassel, D. R. (2009) Neuropeptide signaling near and far: how localized and timed is the action of neuropeptides in brain circuits? Invertebr. Neurosci. 9, 57-75.

(38) Fellowes, R. A., Dougan, P. M., Maule, A. G., Marks, N. J., and Halton, D. W. (1999) Neuromusculature of the ovijector of ascaris suum (Ascaroidea, nematoda): an ultrastructural and immunocytochemical study. J. Comp. Neurol. 415, 518-528.

(39) Moffett, C. L., Beckett, A. M., Mousley, A., Geary, T. G., Marks, N. J., Halton, D. W., Thompson, D. P., and Maule, A. G. (2003) The ovijector of Ascaris suum: multiple response types revealed by Caenorhabditis elegans FMRFamide-related peptides. Int. J. Parasitol. 33, 859-876.
(40) McVeigh, P., Geary, T. G., Marks, N. J., and Maule, A. G. (2006) The FLP-side of nematodes. Trends Parasitol. 22, 385-396.

(41) Atkinson, L. E., Miskelly, I. R., Moffett, C. L., McCoy, C. J., Maule, A. G., Marks, N. J., and Mousley, A. (2016) Unraveling flp-11/ flp-32 dichotomy in nematodes. Int. J. Parasitol. 46, 723-736.

(42) Fellowes, R. A., Maule, A. G., Marks, N. J., Geary, T. G., Thompson, D. P., Shaw, C., and Halton, D. W. (1998) Modulation of the motility of the vagina vera of Ascaris suum in vitro by FMRF amide-related peptides. Parasitology 116 (3), 277-287.

(43) Fellowes, R. A., Maule, A. G., Martin, R. J., Geary, T. G., Thompson, D. P., Kimber, M. J., Marks, N. J., and Halton, D. W. (2000) Classical neurotransmitters in the ovijector of Ascaris suum: localization and modulation of muscle activity. Parasitology 121 (3), 325-336.

(44) Nanda, J. C., and Stretton, A. O. (2010) In situ hybridization of neuropeptide-encoding transcripts afp-1, afp-3, and afp-4 in neurons of the nematode Ascaris suum. J. Comp. Neurol. 518, 896-910.

(45) Konop, C. J., Knickelbine, J. J., Sygulla, M. S., Vestling, M. M., and Stretton, A. O. (2015) Different neuropeptides are expressed in different functional subsets of cholinergic excitatory motorneurons in the nematode Ascaris suum. ACS Chem. Neurosci. 6, 855-870.

(46) Anderson, R. C., Newton, C. L., Millar, R. P., and Katz, A. A. (2014) The Brugia malayi neuropeptide receptor-4 is activated by FMRFamide-like peptides and signals via G $\alpha$ i. Mol. Biochem. Parasitol. 195, 54-58.

(47) Nagashima, T., Oami, E., Kutsuna, N., Ishiura, S., and Suo, S. (2016) Dopamine regulates body size in Caenorhabditis elegans. Dev. Biol. 412, 128-138.

(48) Kage-Nakadai, E., Kobuna, H., Kimura, M., Gengyo-Ando, K., Inoue, T., Arai, H., and Mitani, S. (2010) Two very long chain fatty acid acyl-CoA synthetase genes, acs-20 and acs-22, have roles in the cuticle surface barrier in Caenorhabditis elegans. PLoS One 5, No. e8857.

(49) Li, C., and Kim, K. (2014) Family of FLP Peptides in Caenorhabditis elegans and Related Nematodes. Front. Endocrinol. 5, 150.

(50) Howe, K. L., Bolt, B. J., Cain, S., Chan, J., Chen, W. J., Davis, P., Done, J., Down, T., Gao, S., Grove, C., Harris, T. W., Kishore, R., Lee, R., Lomax, J., Li, Y., Muller, H. M., Nakamura, C., Nuin, P., Paulini, M., Raciti, D., Schindelman, G., Stanley, E., Tuli, M. A., Van Auken, K., Wang, D., Wang, X., Williams, G., Wright, A., Yook, K., Berriman, M., Kersey, P., Schedl, T., Stein, L., and Sternberg, P. W. (2016) WormBase 2016: expanding to enable helminth genomic research. Nucleic Acids Res. 44, D774-780.

(51) Bolt, B. J., Rodgers, F. H., Shafie, M., Kersey, P. J., Berriman, M., and Howe, K. L. (2018) Using WormBase ParaSite: An Integrated Platform for Exploring Helminth Genomic Data. Methods Mol. Biol. 1757, 471-491.

(52) Howe, K. L., Bolt, B. J., Shafie, M., Kersey, P., and Berriman, M. (2017) WormBase ParaSite-a comprehensive resource for helminth genomics. Mol. Biochem. Parasitol. 215, 2-10.

(53) Holterman, M., van der Wurff, A., van den Elsen, S., van Megen, H., Bongers, T., Holovachov, O., Bakker, J., and Helder, J. (2006) Phylum-wide analysis of SSU rDNA reveals deep phylogenetic relationships among nematodes and accelerated evolution toward crown Clades. Mol. Biol. Evol. 23, 1792-1800.

(54) Simao, F. A., Waterhouse, R. M., Ioannidis, P., Kriventseva, E. V., and Zdobnov, E. M. (2015) BUSCO: assessing genome assembly and annotation completeness with single-copy orthologs. Bioinformatics 31, 3210-3212.

(55) Parra, G., Bradnam, K., and Korf, I. (2007) CEGMA: a pipeline to accurately annotate core genes in eukaryotic genomes. Bioinformatics 23, 1061-1067.

(56) Stiernagle, T. (2006) Maintenance of C. elegans. WormBook, $1-11$.

(57) Porta-de-La-Riva, M., Fontrodona, L., Villanueva, A., and Ceron, J. (2012) Basic Caenorhabditis elegans methods: synchronization and observation. J. Visualized Exp., No. e4019. 
(58) Wang, J., Gao, S., Mostovoy, Y., Kang, Y., Zagoskin, M., Sun, Y., Zhang, B., White, L. K., Easton, A., Nutman, T. B., Kwok, P. Y., Hu, S., Nielsen, M. K., and Davis, R. E. (2017) Comparative genome analysis of programmed DNA elimination in nematodes. Genome Res. 27, 2001-2014.

(59) Wang, J., Mitreva, M., Berriman, M., Thorne, A., Magrini, V., Koutsovoulos, G., Kumar, S., Blaxter, M. L., and Davis, R. E. (2012) Silencing of germline-expressed genes by DNA elimination in somatic cells. Dev. Cell 23, 1072-1080.

(60) McCoy, C. J., Atkinson, L. E., Zamanian, M., McVeigh, P., Day, T. A., Kimber, M. J., Marks, N. J., Maule, A. G., and Mousley, A. (2014) New insights into the FLPergic complements of parasitic nematodes: Informing deorphanisation approaches. EuPa Open Proteomics 3, 262-272.

(61) McKay, F. M., McCoy, C. J., Marks, N. J., Maule, A. G., Atkinson, L. E., and Mousley, A. (2021) In silico analyses of neuropeptide-like protein (NLP) profiles in parasitic nematodes. bioRxiv, DOI: 10.1101/2021.03.03.433794.

(62) Van Sinay, E., Mirabeau, O., Depuydt, G., Van Hiel, M. B., Peymen, K., Watteyne, J., Zels, S., Schoofs, L., and Beets, I. (2017) Evolutionarily conserved TRH neuropeptide pathway regulates growth in Caenorhabditis elegans. Proc. Natl. Acad. Sci. U. S. A. 114, E4065-e4074.

(63) Schneider, C. A., Rasband, W. S., and Eliceiri, K. W. (2012) NIH Image to ImageJ: 25 years of image analysis. Nat. Methods 9, 671-675.

(64) Chojnacki, S., Cowley, A., Lee, J., Foix, A., and Lopez, R. (2017) Programmatic access to bioinformatics tools from EMBL-EBI update: 2017. Nucleic Acids Res. 45, W550-w553.

(65) Mistry, J., Finn, R. D., Eddy, S. R., Bateman, A., and Punta, M. (2013) Challenges in homology search: HMMER3 and convergent evolution of coiled-coil regions. Nucleic Acids Res. 41, No. e121.

(66) McVeigh, P., McCammick, E., McCusker, P., Wells, D., Hodgkinson, J., Paterson, S., Mousley, A., Marks, N. J., and Maule, A. G. (2018) Profiling G protein-coupled receptors of Fasciola hepatica identifies orphan rhodopsins unique to phylum Platyhelminthes. Int. J. Parasitol.: Drugs Drug Resist. 8, 87-103.

\section{NOTE ADDED AFTER ASAP PUBLICATION}

Originally published ASAP on August 4, 2021; Table 1 revised on August 12, 2021 as a result of production error. 